\title{
Temporal dynamics of base excision / single-strand break repair protein complex assembly and disassembly are modulated by the PARP1/NAD + /SIRT 6 axis
}

\author{
Christopher A. Koczor ${ }^{1,2}$, Kate M. Saville ${ }^{1,2}$, Joel F. Andrews ${ }^{1}$, Jennifer Clark $^{1,2}$, Qingming \\ Fang ${ }^{1,2}$, Jianfeng $\mathrm{Li}^{1,2}$, Mikhail V. Makarov ${ }^{1,2}$, Marie Migaud ${ }^{1,2}$ and Robert W. Sobol*1,2
}

\footnotetext{
Affiliations

${ }^{1}$ Mitchell Cancer Institute, University of South Alabama, Mobile, AL 36604, USA

${ }^{2}$ Department of Pharmacology, College of Medicine, University of South Alabama, Mobile, AL 36604, USA
}

\section{${ }^{*}$ Correspondence:}

Robert W. Sobol, PhD; Mitchell Cancer Institute, University of South Alabama, 1660 Springhill Avenue, Mobile, AL 36604, USA.

E-mail: rwsobol@southalabama.edu 


\section{SUMMARY}

Assembly and disassembly of DNA repair protein complexes at sites of DNA damage is essential to maintain genomic integrity. We investigated factors coordinating assembly of the base excision repair (BER) proteins, DNA polymerase $\beta(P o l \beta)$ and XRCC1, to DNA lesion sites, identifying a new role for $P o l \beta$ in regulating XRCC1 disassembly from DNA repair complexes and conversely, demonstrating Pol $\beta$ 's dependence on XRCC1 for complex assembly. RealPAR, a genetically-encoded probe for live cell imaging of poly(ADP-ribose) (PAR), reveals that Pol $\beta$ and XRCC1 require PAR for repair complex assembly and PAR degradation for disassembly. We find that BER complex assembly is further modulated by attenuation / augmentation of $\mathrm{NAD}^{+}$biosynthesis. Finally, SIRT6 does not regulate PARP1 activation but impairs XRCC1 recruitment, leading to diminished Pol $\beta$ abundance at sites of DNA damage. These findings highlight coordinated yet independent roles for both PARP1 and SIRT6 and their regulation by NAD ${ }^{+}$ bioavailability to facilitate BER.

Key Words: DNA polymerase $\beta, \mathrm{XRCC1}$, poly(ADP-ribose), PAR, NAD ${ }^{+}, \mathrm{NRH}, \mathrm{BER}$, SSBR, SIRT6, ReaIPAR 


\section{INTRODUCTION}

DNA damage-induced genomic instability is a well-documented phenotype in both aging and cancer. Multiple DNA repair pathways facilitate repair of the damage, with each pathway specializing in the repair of specific DNA lesions. These repair pathways rely on the coordinated expression, synthesis and post-translational modification of multiple proteins and the bioavailability of regulatory factors to repair the DNA lesion, including 1) signaling to promote chromatin access and DNA repair complex assembly, 2) localization of repair complex scaffold proteins, 3 ) activity of enzymatic repair proteins, 4) disassembly of the repair complex and finally, 5) chromatin reorganization.

Base excision repair (BER) and single-strand break repair (SSBR) mechanisms facilitate repair of base damage and DNA single-strand breaks (Abbotts and Wilson, 2017; Svilar et al., 2011) (Figure 1A). Short-patch BER begins with removal of the damaged base by a DNA glycosylase to hydrolyze the $\mathrm{N}$-glycosidic bond between the nucleobase and the phosphodiester riboside backbone. The resulting apurinic/apyrimidinic (AP) site is processed 5' to the AP site by AP-endonuclease 1 (APE1) and the resulting gap is tailored by the 5'-deoxyribosephosphate (dRP) lyase function of DNA polymerase $\beta$ (Pol $\beta$ ) (Sobol et al., 2000; Wilson and Barsky, 2001). This yields a single-strand break that is processed by Pol $\beta$ 's nucleotidyl-transferase activity to insert a new base, followed by DNA ligase 1 (LIG1) or DNA ligase 3 (LIG3)-mediated ligation to seal the phosphodiester backbone. In the case of SSBR, a single strand break (similar to the intermediate observed during BER) undergoes gap tailoring by APE 1 and Pol $\beta$ to ensure the break is a substrate for new base addition by Pol $\beta$. Short-patch BER and SSBR can diverge depending on the 5 ' and 3 ' terminal blocking lesions and whether they are substrates for Pol $\beta$ and APE1 (Abbotts and Wilson, 2017).

For the efficient recruitment of BER/SSBR proteins to sites of damage, multiple factors must work in coordination. X-ray repair cross complementing 1 (XRCC1) functions as a scaffold protein that localizes repair proteins (including Pol $\beta$ and DNA ligase 3 ) to DNA damage sites, thereby facilitating BER/SSBR repair (Almeida and Sobol, 2007; London, 2015). XRCC1 is recruited through its poly(ADP-ribose) (PAR) binding domain, which 
binds to PAR chains formed by activated poly(ADP-ribose) polymerases (PARPs) at sites of DNA damage (Breslin et al., 2015; El-Khamisy et al., 2003). Loss of one or more of these assembly intermediates or proteins would be expected to compromise BER/SSBR complex formation by reducing Pol $\beta$ localization to sites of DNA damage. This appears to be the case for NAD+-dependent protein deacetylase sirtuin-6 (SIRT6). Loss of SIRT6 in mammalian cells and mice induces increased genomic instability and enhanced sensitivity to DNA alkylation and oxidation damage (Mostoslavsky et al., 2006). The mechanism for this instability has not been fully characterized, although it has been shown that enhancing Pol $\beta$ 's dRP lyase function through over-expression rescued cellular sensitivity to DNA alkylation damage (Mostoslavsky et al., 2006).

Another factor critical to genome stability is the co-factor nicotinamide adenine dinucleotide $\left(\mathrm{NAD}^{+}\right.$) (Fouquerel and Sobol, 2014). A deficiency in $\mathrm{NAD}^{+}$can lead to decreased PARP and sirtuin activity, promoting genomic instability and a decrease in DNA repair capacity (Fouquerel et al., 2014). The cofactor NAD ${ }^{+}$is a required substrate to enable PARP-mediated PAR formation at sites of DNA damage (Rouleau et al., 2010). Additionally, $\mathrm{NAD}^{+}$is required by sirtuins (such as SIRT6) to perform a number of genome stabilizing activities (Imai and Guarente, 2014). NAD ${ }^{+}$levels have been shown to deplete with aging (Fang et al., 2017; Imai and Guarente, 2014), during pregnancy (Shi et al., 2017), upon viral infection (Mesquita et al., 2016), and are dysregulated in some cancers (Chiarugi et al., 2012; Yaku et al., 2018). Augmenting NAD+ through pharmacological means has been of increasing interest (Giroud-Gerbetant et al., 2019). Dihydronicotinamide riboside $(\mathrm{NRH})$ is a reduced form of nicotinamide riboside (NR) and is uniquely metabolized, leading to enhanced levels of intracellular $\mathrm{NAD}^{+}$(GiroudGerbetant et al., 2019; Yang et al., 2019). Currently, it is unknown how modulating NAD ${ }^{+}$ impacts assembly and disassembly of BER/SSBR complexes at sites of DNA damage.

While the in vitro biochemistry of the proteins in the BER and SSBR pathways have been extensively studied, the mechanisms by which key repair proteins assemble and disassemble at the DNA damage site in the cell are not defined. Biochemical analysis of BER processing of DNA lesions using purified nucleosomes suggests additional factors are likely required to effectively gain access to the DNA lesion for removal and repair 
(Beard et al., 2003; Cole et al., 2010; Rodriguez et al., 2017). Laser micro-irradiation provides real-time assessment of DNA repair in live cells using fluorescently tagged fusion proteins within the cellular context of other factors known to alter DNA repair, including chromatin structure, non-enzymatic accessory proteins, and the cellular metabolic profile. Here, real-time in vivo assembly and disassembly of BER/SSBR complexes were investigated using UVA $(355 \mathrm{~nm})$ laser micro-irradiation to introduce lesions repaired primarily through BER/SSBR (Holton et al., 2017). Knockout of critical proteins demonstrates key steps for Pol $\beta$ and XRCC1 recruitment to and release from sites of micro-irradiation-induced DNA damage. To follow PARP1-activation in real-time, we developed the RealPAR probe, a genetically-encoded PAR monitor, demonstrating an enhanced capability to extend the characterization of BER/SSBR to include real-time PAR formation in vivo (in cells) and its effects on Pol $\beta$ and XRCC1 recruitment. Further, we show that BER/SSBR complex assembly modulated by alterations in NAD bioavailability. Finally, we highlight that, unlike its role in DNA double-strand break repair (DSBR) (Tian et al., 2019), SIRT6 does not regulate PARP1 activation during BER yet negatively impacts XRCC1's complex assembly capacity (independent of PAR formation) and ultimately reduces Pol $\beta$ 's localization to sites of DNA damage. Overall, these studies highlight the coordinated yet independent roles for both PARP1 and SIRT6 and their regulation by $N A D^{+}$to facilitate BER, supporting an essential PARP1-NAD+-SIRT6 axis for BER protein complex assembly dynamics. 


\section{RESULTS}

\section{Dynamics of Pol $\beta$ and XRCC1 base excision repair complex assembly}

To quantitatively assess the recruitment of DNA repair proteins in response to laserinduced micro-irradiation, we used MIDAS (Modular Irradiation, Detection, and Analysis System), a software platform for performing and analyzing micro-irradiation experiments (see Methods). To rapidly identify the recruitment kinetic profiles for individual fluorescently tagged proteins, we utilized the parallel stimulation module in MIDAS to collect time-lapse images of multiple laser-induced DNA damage foci (one per cell nucleus) for quantitative and statistical analysis, irradiating 10 cells per field and acquiring an image every 15 seconds for the duration of the study (either 10 or 20 minutes). Although cells in each image field are irradiated sequentially, cell-specific timing offsets are measured for each irradiation event, allowing for precise calculation of timing on a per-cell basis.

To investigate the Pol $\beta / X R C C 1 / P A R$ axis of base excision repair (BER) (Figure 1A), we established recruitment kinetics for the central protein factors in BER, Pol $\beta$ and XRCC1. Previous studies have demonstrated that $405 \mathrm{~nm}$ laser micro-irradiation introduces both DNA single-strand breaks (SSB) and DNA double-strand breaks (DSB), while $355 \mathrm{~nm}$ lasers can produce BER and SSBR-specific damage (Holton et al., 2017; Lan et al., 2004). Cells expressing the fluorescently tagged DNA double-strand break repair (DSBR) protein 53BP1 are readily recruited to sites of DNA damage induced by $405 \mathrm{~nm}$ microirradiation. However, 53BP1 did not respond to $355 \mathrm{~nm}$ micro-irradiation, verifying at those settings that the $355 \mathrm{~nm}$ laser does not produce measurable recruitment of DSBresponsive proteins (Figures S1A and S1B). Thus, using $355 \mathrm{~nm}$ stimulation allows investigation of the response of Pol $\beta$ and XRCC1 to BER/SSBR selective DNA damage in the absence of significant DNA double-stranded break repair and response from DSBR proteins. 
Pol $\beta$ and XRCC1 recruited rapidly to 355nm laser-induced DNA damage in U2OS cells (Figure 1B, C, and S1C). Previous research by our lab and others supports a paradigm where Pol $\beta$ and XRCC1 form a heterodimer during DNA repair, which suggests similar DNA damage-induced recruitment profiles (Almeida and Sobol, 2007; Fang et al., 2019; Fang et al., 2014). However, Pol $\beta$ was found to reach maximum recruitment capacity more rapidly (30s to peak intensity) than XRCC1 ( 116s). Recruitment of Pol $\beta$ and XRCC1 was verified in a second cell line (A549 cells), though recruitment peaks were delayed for both repair proteins in the A549 cell line, demonstrating the importance of cell-type specific context for repair complex assembly and disassembly (Figures S1D-E).

\section{RealPAR enables real-time, live cell poly(ADP-ribose) (PAR) imaging}

Due to the significance of PAR synthesis in promoting BER/SSBR complex assembly at sites of DNA damage, immunocytochemistry and PAR antibodies are routinely utilized to verify PAR formation at the site of damage, coincident with EGFP-Pol $\beta$ recruitment (Figure S1F). However, this method has multiple drawbacks when compared to live-cell fluorescence imaging, including experimental variability in fixation and labeling methods as well as reduced temporal resolution due to cell fixation time. We developed a novel fluorescently tagged PAR-detecting fusion protein referred to as RealPAR (Figure 1D). Nine PAR binding domains (PBD) from known PAR-binding proteins were identified, with domains known to bind to different PAR chain moieties (Supplemental Table S1) (Teloni and Altmeyer, 2016). Each PBD was fused to a C-terminal EGFP domain, expressed in cells, and imaged to ensure expression of the fusion protein and validate sub-cellular localization, if any (Figure S1G). We visualized the response of each fusion protein to 355nm laser-induced DNA damage, under similar micro-irradiation conditions employed for Pol $\beta$ and XRCC1 recruitment. Among the nine fusion proteins, only one (hereafter termed RealPAR) demonstrated recruitment to sites of $355 \mathrm{~nm}$ micro-irradiation and was readily expressed in multiple cell types (Figure 1E, F, and S1C). Furthermore, 405nm micro-irradiation (which produces more DSBs but also elicits PAR formation) also promoted RealPAR's recruitment to DNA damage-induced foci, verifying that RealPAR is 
recruited to at least two known PAR-generating micro-irradiation wavelengths (Figure S1H). The RealPAR PBD has been investigated previously, and mutations that eliminate PAR binding have been characterized (Wang et al., 2012). Expression of RealPAR harboring one of these mutations (Y107A) was sufficient to prevent RealPAR recruitment to micro-irradiation induced sites of DNA damage (Figure 1F). Finally, to determine if RealPAR's recruitment was sensitive to and dependent on PAR formation and degradation, cells expressing RealPAR were treated with the PARP inhibitor ABT-888 or the PARG inhibitor PDD00017273 (Donawho et al., 2007; James et al., 2016). While PARP inhibition was able to prevent RealPAR's recruitment to laser-induced foci, PARG inhibition enhanced and prolonged RealPAR's recruitment (Figure 1G). RealPAR therefore is a stable, live-cell imaging tool for visualizing PAR formation and degradation in real-time in living cells. Combining RealPAR with laser micro-irradiation yields a powerful experimental platform for probing the mechanistic processes affecting DNA repair complex assembly (Figure $1 \mathrm{~A})$.

We used MIDAS to quantitatively assess recruitment, measuring the time to peak recruitment intensity and half-life of recruitment for Pol $\beta, X R C C 1$, and RealPAR (Figures 1H, I). Pol $\beta$ reached peak recruitment intensity first, followed by XRCC1 and then RealPAR. Similarly, the half-life of recruitment analysis demonstrated that Pol $\beta$ disassembles from the repair complex first, followed by XRCC1 and the degradation of PAR, as evidenced by the long half-life of recruitment for RealPAR. To characterize the early phase of recruitment more precisely, we used MIDAS to perform high-speed singlecell micro-irradiation experiments, using an imaging interval of $250 \mu$ s and a duration of 1 minute. This serial imaging approach was important for accurately characterizing Pol $\beta$, which exhibited the shortest time to peak intensity (Figure 1B). Serial analysis confirmed the 30 s time to peak intensity for Pol $\beta$ following $355 \mathrm{~nm}$ stimulation in U2OS cells (Figure $1 \mathrm{~J}-\mathrm{L})$. 


\section{Over-expression of EGFP-Pol $\beta$ displays similar recruitment kinetics as endogenously tagged EGFP-Pol $\beta$}

While over-expression of fluorescently tagged DNA repair proteins can aid in understanding repair complex assembly kinetics, over-expression could alter repair kinetics by supplementing rate-limiting enzymes. This is important in the case of Pol $\beta$, which is required for short-patch BER, can be rate-limiting, and is the primary gap-tailoring dRP lyase for repair of base lesions (Allinson et al., 2001; Sobol et al., 2000; Srivastava et al., 1998). To address if over-expression altered recruitment kinetics, EGFP cDNA was fused endogenously to the POLB gene in chromosome 8 of A549 cells, thereby preserving the promoter region and allowing expression of the EGFP-Pol $\beta$ protein under endogenous conditions (Figure 2A). We utilized a CRISPR/Cas9 ribonucleoprotein complex along with an oligonucleotide fragment of the POLB homology region around the POLB transcription start site and an in-frame EGFP cDNA. Successful generation of cells expressing EGFP-Pol $\beta$ was confirmed through three independent methods. Sanger sequencing of POLB alleles demonstrated successful targeting of one out of the three alleles in A549 cells (Figure 2B and Supplemental Table S2). One allele had no modification, and the final allele had a partial incorporation that added 45 base pairs 5 ' to POLB exon 1. Immunoblots showed that both EGFP-Pol $\beta$ and non-tagged Pol $\beta$ were produced by the modified A549 cells (Figure 2C; full blots in Figure S2A). Finally, we performed confocal spectral microscopy to confirm that EGFP-Pol $\beta$ was detected in the modified A549 cells. Because expression under the endogenous promoter led to low levels of EGFP fluorescence in the modified cells, we performed spectral imaging and unmixing to remove autofluorescence. Spectral unmixing demonstrated that EGFP-Pol $\beta$ expression was primarily in the nuclear compartment, with a minor fraction in the cytosolic compartment, consistent with the distribution observed in EGFP-Pol $\beta$ overexpressing cells (Figure 2D and S2B). Finally, we performed 355nm micro-irradiation on the endogenously tagged A549/EGFP-Pol $\beta$ cells. Endogenous EGFP-Pol $\beta$ recruited to sites of 355nm laser-induced DNA damage, and recruitment kinetics were found to be similar to the recruitment kinetics of over-expressed EGFP-Pol $\beta$ (Figures 2D-G). The half-life of recruitment for the endogenously tagged EGFP-Pol $\beta$ was significantly reduced as 
compared to over-expressed EGFP-Pol $\beta$ in A549 cells (Figure 2G). This may be a result of the increased amount of Pol $\beta$ protein that can recruit to the site of damage in overexpression models, resulting in a slight increase in the time required to disassemble the Pol $\beta$ complex. Overall, over-expression of EGFP-Pol $\beta$ does not lead to gross changes in recruitment kinetics when compared to EGFP-Pol $\beta$ expressed at endogenous levels.

\section{Loss of Pol $\beta$ enzymatic activity does not alter damage-induced recruitment kinetics}

Pol $\beta$ has two enzymatic functions: (i) a 5 'dRP lyase activity that can be significantly attenuated by an alanine mutation at amino acid residue K72 (K72A) and (ii) a polymerase or nucleotidyl-transferase activity that can be eliminated by an alanine mutation at residue D256 (D256A) (Matsumoto et al., 1998; Menge et al., 1995). Loss of the 5'dRP lyase activity of Pol $\beta$, but not its polymerase activity, sensitizes cells to genotoxic damage, suggesting loss of the 5 'dRP lyase activity may enhance retention of Pol $\beta$ to sites of DNA damage (Sobol et al., 2000). To investigate the role of Pol $\beta$ 's enzymatic activities on its recruitment and retention to DNA damage sites, EGFP-Pol $\beta$, EGFP-Pol $\beta(K 72 A)$ and EGFP-Pol $\beta$ (D256A) were expressed in U2OS cells. Surprisingly, no significant changes in recruitment kinetic profiles, time to peak intensity, or half-life of recruitment were observed (Figures $3 \mathrm{~A}-\mathrm{C}$ ). As it is conceivable that endogenous Pol $\beta$ was contributing to the repair of the laser-induced DNA damage, the WT and mutant fusions were modified to be gRNA resistant (using a silent mutation) and then expressed in U2OS/POLB-KO cells (Figure 3D). However, loss of endogenous Pol $\beta$ had no effect on the recruitment profiles of either the dRP lyase or polymerase mutants (Figure 3E). This was unexpected, as previous studies have shown that $P$ ol $\beta(K 72 A)$-expressing mouse fibroblasts are hypersensitive to DNA damage (Sobol et al., 2000). One explanation may be that the Pol $\beta(K 72 A)$ mutant retains $\sim 1 \%$ residual 5 'dRP lyase activity, which may contribute to DNA repair (Matsumoto et al., 1998). To address this, an EGFP-Pol $\beta 5$ 'dRP lyase triple mutant, Pol $\beta(\mathrm{K} 35 \mathrm{~A} / \mathrm{K} 68 \mathrm{~A} / \mathrm{K} 72 \mathrm{~A})$, completely devoid of 5 'dRP lyase activity (Sobol et al., 2000), was expressed in the U2OS/POLB-KO cells. The EGFP-Pol $\beta$ 5'dRP lyase triple 
mutant did not display altered recruitment profiles as compared to EGFP-Pol $\beta$ in POLB knockout cells (U2OS/POLB-KO) (Figure 3F). To identify if this was a U2OS cell-specific outcome, A549/POLB-KO cells were used to verify the 5'dRP lyase activity mutant results. Again, no change in recruitment was observed in the EGFP-Pol $\beta(K 72 A)$ expressing cells compared to EGFP-Pol $\beta$ (Figures S3A-D). In all, we find that Pol $\beta$ recruitment to and retention at sites of DNA damage is not dependent on either of Pol $\beta$ 's known enzymatic functions.

\section{Pol $\beta$ 's recruitment is dependent on XRCC1, while Pol $\beta$ enables XRCC1 complex disassociation}

Recruitment to and retention of Pol $\beta$ at micro-irradiation-induced DNA damage sites may be regulated through one of its binding partners. A strong candidate for this role is XRCC1, which functions as a scaffold for multiple repair proteins, including Pol $\beta$, at sites of DNA damage (Kubota et al., 1996). To investigate the functionality of this interaction in response to DNA damage, XRCC1 knockout (KO) cells were generated using CRISPRCas9 and verified by immunoblot (Figure 4A, S4). Loss of XRCC1 attenuated Pol $\beta$ recruitment to sites of DNA damage in two independent KO cell lines (Figure 4B). This suggests a requirement for XRCC1 with regard to the recruitment and BER complex assembly for Pol $\beta$, but it does not address if physical binding is required for this effect. The V303 loop of Pol $\beta$ has previously been identified as facilitating the physical interaction of Pol $\beta$ with XRCC1. A separation of function mutation in this loop (i.e. L301R/V303R/V306R, referred to as Pol $\beta(T M))$ reduces the binding affinity between Pol $\beta$ and XRCC1 by greater than 6-fold (Fang et al., 2019; Fang et al., 2014). EGFP-Pol $\beta$ (TM) was expressed in A549 cells expressing endogenous XRCC1 and as predicted, did not visibly recruit to sites of laser micro-irradiation (Figure $4 \mathrm{C}$ ), demonstrating that the physical interaction between Pol $\beta$ and $X R C C 1$ is required to facilitate Pol $\beta$ recruitment.

Because the recruitment of XRCC1 to the site of damage was critical for the recruitment of Pol $\beta$, we then investigated if alterations in Pol $\beta$ could modulate XRCC1 recruitment. 
XRCC1-EGFP recruitment exhibited both enhanced peak recruitment intensity and prolonged recruitment in POLB-KO cells when compared to Pol $\beta$-expressing cells (Figure 4D). This novel finding suggests that $P o l \beta$ is required to facilitate $X R C C 1$ dissociation from assembled DNA repair complexes. To validate if this was the case, Pol $\beta$ and XRCC1-EGFP were co-expressed in POLB-KO cells. By re-expressing Pol $\beta$, we were able to recapitulate $\mathrm{XRCC} 1$ 's disassociation from micro-irradiation-induced foci, thereby demonstrating a requirement for Pol $\beta$ to promote rapid dissociation of XRCC1 from the site of DNA damage (Figure 4E). These results suggest a negative feedback loop in which Pol $\beta$ requires XRCC1 for recruitment to sites of DNA damage, but then itself acts as a regulator of $\mathrm{XRCC} 1$ dissociation from those sites.

The dependence of $\mathrm{XRCC} 1$ on Pol $\beta$ for dissociation may be mediated by enhanced PARylation at the site of DNA damage in the absence of Pol $\beta$, as Pol $\beta$ loss would likely lead to prolonged PAR formation at the site of damage (Jelezcova et al., 2010; Tang et al., 2010). To determine if this was caused by altered PAR formation, we utilized the RealPAR probe to interrogate PAR dynamics in POLB-KO cells. PARylation was enhanced in POLB-KO cells compared to normal cells, but the rate of PAR degradation, as inferred from the change in RealPAR binding, was similar in POLB-KO cells compared to Pol $\beta$ expressing cells (Figure 4F), suggesting that the requirement of Pol $\beta$ for $X R C C 1$ 's rapid complex disassociation is not dependent on PAR formation.

\section{Pol $\beta$ and XRCC1 complex dynamics depend on PAR formation and degradation}

PARylation is a critical component of BER/SSBR (Dantzer et al., 2000; Schreiber et al., 2002), so we investigated how PARylation alters Pol $\beta / X R C C 1$ repair complex assembly. To identify how PARP1 regulates Pol $\beta$ complex assembly, PARP1 knockout cells were generated and validated by immunoblot (Figure 5A). Pol $\beta$ recruitment was attenuated but not eliminated in PARP1 knockout cells, which is consistent with previous findings that other PARPs (such as PARP2) promote PARylation and DNA repair complex assembly during BER (Figure 5B) (Dantzer et al., 2000; Schreiber et al., 2002). To 
address the role of PARylation in Pol $\beta / X R C C 1 / P A R$ repair complex assembly and disassembly more broadly, the PARP inhibitor ABT-888 (velipirab) and the PARG inhibitor PDD00017273 were used. As shown above, PARylation, as determined by the recruitment of the RealPAR probe, was abolished with ABT-888 treatment while PARG inhibition enhanced and prolonged PAR formation at sites of laser micro-irradiation (Figure 1G). Pol $\beta$ and XRCC1 behaved similarly, showing attenuation of recruitment upon PARP inhibition and prolonged recruitment and retention following PARG inhibition (Figures 5C-D). PARylation synthesis and degradation therefore temporally regulate Pol $\beta$ and XRCC1 repair complex assembly and disassembly at sites of DNA damage. In addition to PARG's degradation of PAR from sites of DNA damage, TARG (OARD1) serves to degrade PAR by removing the O-acyl-ADP-ribose moiety that is the first ADPribose added to a PAR chain (Sharifi et al., 2013). To determine if TARG impacts Pol $\beta$ complex formation, TARG was knocked out using CRISPR/Cas9 (Figure S5A), but no change in Pol $\beta$ recruitment kinetics was observed (Figure S5B).

\section{Pol $\beta$ and XRCC1 complex assembly is regulated by $N A D^{+}$availability}

$\mathrm{NAD}^{+}$is a metabolic product and regulator that is an essential substrate for PARPs to produce PAR chains (Fouquerel and Sobol, 2014; Rouleau et al., 2010). Because PAR is necessary for Pol $\beta$ and XRCC1 recruitment to DNA damage, modulation of NAD ${ }^{+}$ should lead to changes in Pol $\beta$ and XRCC1 recruitment. To identify how NAD ${ }^{+}$availability affects Pol $\beta / X R C C 1$ repair complex formation, the NAMPT inhibitor FK866 was used to decrease cellular $\mathrm{NAD}^{+}$levels, and dihydronicotinamide riboside $(\mathrm{NRH})$ was used to enhance cellular NAD ${ }^{+}$levels. Due to factors in serum that alter NAD ${ }^{+}$catabolite stability (Wilk et al., 2020), we used heat-inactivated fetal bovine serum (HI-FBS) for these studies. We noted that the recruitment profiles of Pol $\beta$, XRCC1, or RealPAR with HI-FBS, as compared to normal fetal bovine serum, were unchanged (Figures S6A-C).

FK866 treatment diminished $\mathrm{NAD}^{+}$levels in U2OS cells to $23 \%$ of control (Figure 6A). Since the conversion of $\mathrm{NRH}$ to $\mathrm{NAD}^{+}$is dependent on the metabolic profile of the cell, with maximal $\mathrm{NAD}^{+}$enhancement observed at different times in different cells (Giroud- 
Gerbetant et al., 2019; Yang et al., 2019), a time-course was performed in U2OS cells to identify when $\mathrm{NAD}^{+}$levels were maximally enhanced following $\mathrm{NRH}$ administration (Figure 6B). A peak in $\mathrm{NAD}^{+}$concentration was observed at 4 hours post-NRH addition ( $850 \%$ increase), with $\mathrm{NAD}^{+}$diminishing but remaining above controls for up to 8 hours post-treatment. NRH also enhanced PARP1 activation capacity and DNA damageinduced $\left(\mathrm{H}_{2} \mathrm{O}_{2}\right)$ PARylation in U2OS cells, an effect attenuated by FK866 or ABT888 treatment (Figure 6C). In laser micro-irradiation experiments, $\mathrm{NRH}$ enhanced peak recruitment intensities of Pol $\beta$ (45\%), XRCC1 (94\%), and RealPAR (88\%) (Figures 6DF). Conversely, FK866 reduced peak recruitment intensities of Pol $\beta$ ( $37 \%$ of control), XRCC1 (35\%), and RealPAR (24\%) (Figure 6G-I). No change in the time to peak recruitment intensity or half-life of recruitment was observed, suggesting that $\mathrm{NAD}^{+}$ availability does not impact repair complex assembly or disassembly other than to increase the magnitude of the recruitment.

To determine the broad applicability of $\mathrm{NRH}$ for enhancing intracellular $\mathrm{NAD}^{+}$, the same assays were also performed in A549 cells. Interestingly, $\mathrm{NRH}$ did not significantly increase $\mathrm{NAD}^{+}$in $\mathrm{A} 549$ cells (Figure 6B), possibly due to the low expression of adenosine kinase in this cell line (Protein-Atlas, 2020; Uhlen et al., 2017; Yang et al., 2020). It is possible that $\mathrm{NAD}^{+}$formed via NRH metabolism was being converted into NADH in A549 cells, but we found no changes in NADH following NRH supplementation, in either A549 or U2OS cells (Figure S6D). Utilization of U2OS and A549 cell lines provided a unique opportunity to identify effects (if any) of $\mathrm{NRH}$ on DNA repair complex assembly independent of its $\mathrm{NAD}^{+}$-enhancing capability. Following NRH treatment $(100 \mu \mathrm{M}, 4 \mathrm{hrs})$, A549 did not demonstrate enhanced Pol $\beta, X R C C 1$, or RealPAR recruitment kinetics (Figures S6E-G). In all, we find that NRH's ability to enhance NAD ${ }^{+}$is dependent on the ability of a cell to metabolize $\mathrm{NRH}$ into $\mathrm{NAD}^{+}$, and $\mathrm{NRH}^{\prime}$ enhancement of $\mathrm{NAD}^{+}$directly impacts damage-induced PAR synthesis and the recruitment of Pol $\beta, X R C C 1$, and ReaIPAR to sites of DNA damage. 


\section{Loss of SIRT6 impairs Pol $\beta$ and XRCC1 complex assembly without altering PAR formation}

SIRT6 was previously documented to play a critical and essential role in BER mediated repair but the exact mechanism has never been resolved. Loss of SIRT6 enhanced genomic instability caused by alkylation and oxidation damage, and supplementation of SIRT6-deficient cells with Polß's dRP lyase domain was able to protect against SIRT6KO genotoxic sensitivity (Mostoslavsky et al., 2006). It was suggested that SIRT6 may modulate repair by regulating PARP1 (Mao et al., 2011) such that SIRT6 is required for PARP1 activation in DSB repair (Tian et al., 2019). We therefore utilized RealPAR together with the Pol $\beta$ and XRCC1 fusion proteins to evaluate the role of SIRT6 on Pol $\beta$ and XRCC1 recruitment and PAR formation in response to DNA damage in WT and SIRT6-KO cells (Figure 7A). Both Pol $\beta$ and XRCC1 demonstrated significantly diminished recruitment to DNA damage in SIRT6 knockout cells (Figures 7B-C). However, loss of SIRT6 did not lead to a change in RealPAR focal recruitment, demonstrating that PAR formation was not altered in SIRT6-KO cells (Figure 7D). Together, these results support a model where SIRT6 enhances XRCC1's binding to PAR at sites of DNA damage, and loss of SIRT6 diminishes XRCC1 (and by extension Pol $\beta$ ) recruitment to sites of DNA damage (Figure 7E). 


\section{DISCUSSION}

The characterization of DNA repair complex assembly and disassembly remains an intensive area of investigation for multiple biological fields, including cancer and aging. Identification of key substrates, enzymatic proteins, and accessory factors are key in refining our models of DNA repair pathway control and cross-talk. Here, we investigated the formation of BER/SSBR complex assembly and disassembly in live cells using laser micro-irradiation. While the sequence of enzymatic steps required to repair BER/SSBR lesions has been biochemically characterized using in vitro assays, laser micro-irradiation of fluorescently tagged repair proteins enables interrogation of the repair process within an intact cellular context, allowing analysis of the effects of loss or modulation of key DNA repair components. We used the novel MIDAS system to acquire time-lapse images of laser-induced fusion protein recruitment, detection and quantitation of repair foci in resulting images, and analysis of recruitment kinetics for key parameters.

We first identified the recruitment kinetics of Pol $\beta$ and $X R C C 1$, confirming that Pol $\beta$ 's recruitment was attenuated in XRCC1 knockout cells and was dependent on its V303 loop as previously described (Figure 4C) (Fang et al., 2014). Interestingly, we observed Pol $\beta$ dissociating from the repair complex before XRCC1 (Figures 1B-C). This was unexpected because Pol $\beta$ and XRCC1 are thought to form a heterodimer during repair and it was anticipated that recruitment profiles of $P$ ol $\beta$ and $X R C C 1$ should be similar (Fang et al., 2014). We considered that over-expression of the enzymatic component of the repair complex (EGFP-Pol $\beta$ ) might enable faster repair of the DNA damage, as compared to cells with lower levels of the EGFP-Pol $\beta$ fusion protein. This might then explain why EGFP-Pol $\beta$ over-expressing cells were displaying faster recruitment kinetics, but experiments using endogenously tagged Pol $\beta$ demonstrated that this was not the case (Figure 2). It is currently unknown if $\mathrm{Pol} \beta$ and $X R C C 1$ are recruited as a heterodimer to sites of DNA damage or if they combine at the site, but we observed no difference in $X R C C 1$ 's ability to assemble at sites of DNA damage when Pol $\beta$ was knocked out (Figure 4D). In either case, the results suggest that $P o l \beta$ is being removed from the site prior to 
XRCC1, which implicates an additional control mechanism for Pol $\beta$ repair complex disassembly.

Because our model predicted that XRCC1 recruitment was dependent on PAR but not on Pol $\beta$, we investigated if loss of Pol $\beta$ affected XRCC1 recruitment. Our results showed that loss of Pol $\beta$ enhanced XRCC1 recruitment but also increased XRCC1 retention to sites of laser-induced damage (Figure 4D). Conversely, re-expression of Pol $\beta$ in POLB knockout cells restored XRCC1's disassembly kinetics (Figure 4E). This was a novel finding but could be explained by incomplete repair of the damage site due to a lack of Pol $\beta$ 's enzymatic activities. However, neither EGFP-tagged mutants for Pol $\beta$ 's dRP lyase (K72A or K35A/K68A/K72A) nor polymerase (D256A) activities demonstrated altered recruitment kinetics compared to functional Pol $\beta$ (Figures 3A), even when endogenous Pol $\beta$ was removed (Figures 3E-F). These results have two implications. First, the results identify a novel non-enzymatic function of $P o l \beta$ in facilitating XRCC1 repair complex disassembly. Second, it shows that neither the dRP lyase or polymerase activity of Pol $\beta$ is required for assembly or disassembly of $P o l \beta$ at repair foci. Together, these results support a model where Pol $\beta$ 's recruitment to and dissociation from repair complexes is not dependent on repair of the DNA lesion itself (or repair is facilitated by compensatory enzymes), and that Pol $\beta$ further facilitates removal of XRCC1 from the DNA damage sites. This model is further supported by the lack of change observed in assembly/disassembly kinetics between EGFP-Pol $\beta$ over-expression and endogenously expressed EGFP-Pol $\beta$ (Figure 2E).

Due to the dependence of Pol $\beta$ and XRCC1 on PAR formation for repair, we investigated the role of PAR on recruitment dynamics. Previous micro-irradiation research has utilized PAR antibodies to characterize PAR formation in cells. The results can be impacted by the fixation method used, the antibody used and is hampered by the loss of temporal resolution (a key concern for short time frames). To address this limitation, we developed the novel RealPAR probe to provide real-time, live-cell imaging of PAR formation at sites of laser micro-irradiation (Figure 1D-E). RealPAR's focal recruitment is dependent on its ability to bind PAR and as we show, does not require BrdU or Hoechst sensitization for 
recruitment visualization using either $355 \mathrm{~nm}$ and $405 \mathrm{~nm}$ laser wavelengths. Further, we show that RealPAR is responsive at micro-irradiation settings that elicit Pol $\beta$ and XRCC1 recruitment, two factors whose recruitment is dependent on PAR formation. We confirmed that PARP inhibition prevented PAR formation at sites of laser-induced DNA damage and was required for Pol $\beta$ and XRCC1 recruitment, while loss of PAR degradation enhanced retention of Pol $\beta$ and XRCC1 at sites of damage (Figures $5 C-D$ ). These experiments confirmed that the presence of PAR at sites of DNA damage is a critical step for Pol $\beta$ and XRCC1 recruitment.

$\mathrm{NAD}^{+}$supports DNA repair by serving as a substrate for both PARPs and sirtuins. Depleted $\mathrm{NAD}^{+}$intracellular pools have been linked to decreased genomic integrity, and attempts to boost $\mathrm{NAD}^{+}$as a mechanism for promoting genomic integrity remains active pursuits in the aging field (Fang et al., 2017). Here, we utilized NRH to promote intracellular $\mathrm{NAD}^{+}$pools. $\mathrm{NRH}$ has been shown to enhance $\mathrm{NAD}^{+}$in multiple cell types, with greater increases in $\mathrm{NAD}^{+}$as compared to other $\mathrm{NAD}^{+}$supplements (GiroudGerbetant et al., 2019; Yang et al., 2019). We demonstrated that NRH supplementation enhances intracellular $\mathrm{NAD}^{+}$in U2OS cells, leading to increased assembly of Pol $\beta / X R C C 1$ repair complexes (Figure 6). Interestingly, NRH was unable to enhance $\mathrm{NAD}^{+}$in A549 cells. While the complete mechanism of NRH metabolism is unknown, adenosine kinase (ADK or AK) has been identified as one of the enzymes for $\mathrm{NRH}$ conversion to $\mathrm{NAD}^{+}$, and differential cell expression of ADK can alter $\mathrm{NRH}$ metabolism (Yang et al., 2020).

Finally, we utilized our Pol $\beta / X R C C 1 / R e a I P A R$ system to characterize how deficiency of SIRT6 leads to compromised BER. Loss of SIRT6 enhances cellular sensitivity to genotoxins, while enhancing Pol $\beta$ 's dRP lyase activity attenuates this sensitivity, demonstrating SIRT6's involvement in Pol $\beta$-mediated repair (Mostoslavsky et al., 2006). Our Pol $\beta / X R C C 1 / R e a I P A R$ system provides a unique opportunity to investigate this issue. We found that SIRT6 knockout does not alter PAR formation following microirradiation while XRCC1 recruitment is attenuated (Figure 6D). These results directly implicate SIRT6 in enhancing XRCC1's localization to sites of damage, likely diminishing XRCC1's ability to bind to PAR or be retained at PAR sites. Due to Polß's dependence 
on XRCC1 for repair complex assembly, it was predicted that Pol $\beta$ 's recruitment to sites of DNA damage would also diminish, which we demonstrated (Figure 6B). This result would explain the observations from previous studies where enhancing Pol $\beta$ dRP lyase activity reduces genotoxic sensitivity to SIRT6 loss (Mostoslavsky et al., 2006). Due to the importance of XRCC1 to serve as a scaffold for multiple DNA repair enzymes (e.g. Pol $\beta$, PNKP, APLF, APTX, Liglli) at sites of DNA damage, these results suggest that SIRT6 negatively impacts multiple DNA repair enzymes in BER and SSBR. 


\section{ACKNOWLEDGMENTS}

RWS is an Abraham A. Mitchell Distinguished Investigator. Research in the Sobol lab on DNA repair, the analysis of DNA damage and the impact of genotoxic exposure is funded by grants from the National Institutes of Health (NIH) [CA148629, ES014811, ES029518, ES028949 and CA238061], from the National Science Foundation (NSF) [NSF-1841811] and a grant from the DOD [GRANT11998991, DURIP-Navy]. Support is also provided from the Abraham A. Mitchell Distinguished Investigator Fund and from the Mitchell Cancer Institute Molecular \& Metabolic Oncology Program Develop fund (to RWS). Support for the development of RealPAR was also provided by the Mitchell Cancer Institute Junior Faculty Award (to CAK). We thank Dr. Natalie Gassman (USA Mitchell Cancer Institute) for her invaluable conceptual input on the development of the MIDAS software platform.

\section{AUTHOR CONTRIBUTIONS}

C.A.K., K.M.S., and R.W.S. designed the experiments. C.A.K., K.M.S, J.A., J.C., Q.F., J.L., conducted the experiments, J.F.A. developed software (MIDAS) and M.V.M., M.M. synthesized and provided critical reagents. C.A.K. and R.W.S wrote the paper. All authors read, commented on, and approved the final manuscript version.

\section{CONFLICT OF INTEREST}

RWS is a scientific consultant for Canal House Biosciences, LLC. The authors state that there is no conflict of interest. 


\section{REFERENCES}

Abbotts, R., and Wilson, D.M., 3rd (2017). Coordination of DNA single strand break repair. Free Radic Biol Med 107, 228-244.

Allinson, S.L., Dianova, II, and Dianov, G.L. (2001). DNA polymerase $ß$ is the major dRP lyase involved in repair of oxidative base lesions in DNA by mammalian cell extracts. EMBO Journal 20, 6919-6926.

Almeida, K.H., and Sobol, R.W. (2007). A unified view of base excision repair: lesiondependent protein complexes regulated by post-translational modification. DNA Repair (Amst) 6, 695-711.

Beard, B.C., Wilson, S.H., and Smerdon, M.J. (2003). Suppressed catalytic activity of base excision repair enzymes on rotationally positioned uracil in nucleosomes. Proceedings of the National Academy of Science 100, 7465-7470.

Breslin, C., Hornyak, P., Ridley, A., Rulten, S.L., Hanzlikova, H., Oliver, A.W., and Caldecott, K.W. (2015). The XRCC1 phosphate-binding pocket binds poly (ADP-ribose) and is required for XRCC1 function. Nucleic Acids Res 43, 6934-6944.

Chiarugi, A., Dolle, C., Felici, R., and Ziegler, M. (2012). The NAD metabolome - a key determinant of cancer cell biology. Nature Reviews Cancer.

Cole, H.A., Tabor-Godwin, J.M., and Hayes, J.J. (2010). Uracil DNA glycosylase activity on nucleosomal DNA depends on rotational orientation of targets. J Biol Chem 285, 28762885.

Dantzer, F., de La Rubia, G., Menissier-De Murcia, J., Hostomsky, Z., de Murcia, G., and Schreiber, V. (2000). Base excision repair is impaired in mammalian cells lacking Poly(ADP-ribose) polymerase-1. Biochemistry 39, 7559-7569.

Donawho, C.K., Luo, Y., Penning, T.D., Bauch, J.L., Bouska, J.J., Bontcheva-Diaz, V.D., Cox, B.F., DeWeese, T.L., Dillehay, L.E., Ferguson, D.C., et al. (2007). ABT-888, an orally active poly(ADP-ribose) polymerase inhibitor that potentiates DNA-damaging agents in preclinical tumor models. Clin Cancer Res 13, 2728-2737. 
El-Khamisy, S.F., Masutani, M., Suzuki, H., and Caldecott, K.W. (2003). A requirement for PARP-1 for the assembly or stability of XRCC1 nuclear foci at sites of oxidative DNA damage. Nucleic Acids Research 31, 5526-5533.

Fang, E.F., Lautrup, S., Hou, Y., Demarest, T.G., Croteau, D.L., Mattson, M.P., and Bohr, V.A. (2017). $\mathrm{NAD}(+)$ in Aging: Molecular Mechanisms and Translational Implications. Trends Mol Med 23, 899-916.

Fang, Q., Andrews, J., Sharma, N., Wilk, A., Clark, J., Slyskova, J., Koczor, C.A., Lans, H., Prakash, A., and Sobol, R.W. (2019). Stability and sub-cellular localization of DNA polymerase beta is regulated by interactions with NQO1 and XRCC1 in response to oxidative stress. Nucleic Acids Res 47, 6269-6286.

Fang, Q., Inanc, B., Schamus, S., Wang, X.H., Wei, L., Brown, A.R., Svilar, D., Sugrue, K.F., Goellner, E.M., Zeng, X., et al. (2014). HSP90 regulates DNA repair via the interaction between XRCC1 and DNA polymerase beta. Nature communications 5, 5513.

Fouquerel, E., Goellner, E.M., Yu, Z., Gagne, J.P., Barbi de Moura, M., Feinstein, T., Wheeler, D., Redpath, P., Li, J., Romero, G., et al. (2014). ARTD1/PARP1 negatively regulates glycolysis by inhibiting hexokinase 1 independent of NAD+ depletion. Cell reports $8,1819-1831$.

Fouquerel, E., and Sobol, R.W. (2014). ARTD1 (PARP1) activation and NAD(+) in DNA repair and cell death. DNA Repair (Amst) 23, 27-32.

Giroud-Gerbetant, J., Joffraud, M., Giner, M.P., Cercillieux, A., Bartova, S., Makarov, M.V., Zapata-Perez, R., Sanchez-Garcia, J.L., Houtkooper, R.H., Migaud, M.E., et al. (2019). A reduced form of nicotinamide riboside defines a new path for $N A D(+)$ biosynthesis and acts as an orally bioavailable $\mathrm{NAD}(+)$ precursor. Mol Metab 30, 192202.

Holton, N.W., Andrews, J.F., and Gassman, N.R. (2017). Application of Laser Microirradiation for Examination of Single and Double Strand Break Repair in Mammalian Cells. Journal of visualized experiments : JoVE.

Imai, S., and Guarente, L. (2014). NAD+ and sirtuins in aging and disease. Trends Cell Biol 24, 464-471.

James, D.I., Smith, K.M., Jordan, A.M., Fairweather, E.E., Griffiths, L.A., Hamilton, N.S., Hitchin, J.R., Hutton, C.P., Jones, S., Kelly, P., et al. (2016). First-in-Class Chemical 
Probes against Poly(ADP-ribose) Glycohydrolase (PARG) Inhibit DNA Repair with Differential Pharmacology to Olaparib. ACS chemical biology 11, 3179-3190.

Jelezcova, E., Trivedi, R.N., Wang, X.H., Tang, J.B., Brown, A.R., Goellner, E.M., Schamus, S., Fornsaglio, J.L., and Sobol, R.W. (2010). Parp1 activation in mouse embryonic fibroblasts promotes Pol beta-dependent cellular hypersensitivity to alkylation damage. Mutat Res 686, 57-67.

Kubota, Y., Nash, R.A., Klungland, A., Schar, P., Barnes, D.E., and Lindahl, T. (1996). Reconstitution of DNA base excision-repair with purified human proteins: interaction between DNA polymerase $ß$ and the XRCC1 protein. EMBO Journal 15, 6662-6670.

Lan, L., Nakajima, S., Oohata, Y., Takao, M., Okano, S., Masutani, M., Wilson, S.H., and Yasui, A. (2004). In situ analysis of repair processes for oxidative DNA damage in mammalian cells. Proc Natl Acad Sci U S A 101, 13738-13743.

London, R.E. (2015). The structural basis of XRCC1-mediated DNA repair. DNA Repair (Amst) 30, 90-103.

Mao, Z., Hine, C., Tian, X., Van Meter, M., Au, M., Vaidya, A., Seluanov, A., and Gorbunova, V. (2011). SIRT6 promotes DNA repair under stress by activating PARP1. Science 332, 1443-1446.

Matsumoto, Y., Kim, K., Katz, D.S., and Feng, J.A. (1998). Catalytic center of DNA polymerase $ß$ for excision of deoxyribose phosphate groups. Biochemistry 37, 64566464.

Menge, K.L., Hostomsky, Z., Nodes, B.R., Hudson, G.O., Rahmati, S., Moomaw, E.W., Almassy, R.J., and Hostomska, Z. (1995). Structure-function analysis of the mammalian DNA polymerase beta active site: role of aspartic acid 256, arginine 254, and arginine 258 in nucleotidyl transfer. Biochemistry 34, 15934-15942.

Mesquita, I., Varela, P., Belinha, A., Gaifem, J., Laforge, M., Vergnes, B., Estaquier, J., and Silvestre, R. (2016). Exploring NAD+ metabolism in host-pathogen interactions. Cell Mol Life Sci 73, 1225-1236.

Mostoslavsky, R., Chua, K.F., Lombard, D.B., Pang, W.W., Fischer, M.R., Gellon, L., Liu, P., Mostoslavsky, G., Franco, S., Murphy, M.M., et al. (2006). Genomic instability and aging-like phenotype in the absence of mammalian SIRT6. Cell 124, 315-329. 
Protein-Atlas, H. (2020). http://www.proteinatlas.org. In Protein Atlas version 19.3.

Rodriguez, Y., Howard, M.J., Cuneo, M.J., Prasad, R., and Wilson, S.H. (2017). Unencumbered Pol beta lyase activity in nucleosome core particles. Nucleic Acids Res $45,8901-8915$.

Rouleau, M., Patel, A., Hendzel, M.J., Kaufmann, S.H., and Poirier, G.G. (2010). PARP inhibition: PARP1 and beyond. Nat Rev Cancer 10, 293-301.

Schreiber, V., Ame, J.C., Dolle, P., Schultz, I., Rinaldi, B., Fraulob, V., Menissier-de Murcia, J., and de Murcia, G. (2002). Poly(ADP-ribose) polymerase-2 (PARP-2) is required for efficient base excision DNA repair in association with PARP-1 and XRCC1. Journal of Biological Chemistry 277, 23028-23036.

Sharifi, R., Morra, R., Appel, C.D., Tallis, M., Chioza, B., Jankevicius, G., Simpson, M.A., Matic, I., Ozkan, E., Golia, B., et al. (2013). Deficiency of terminal ADP-ribose protein glycohydrolase TARG1/C6orf130 in neurodegenerative disease. EMBO J 32, 1225-1237.

Shi, H., Enriquez, A., Rapadas, M., Martin, E., Wang, R., Moreau, J., Lim, C.K., Szot, J.O., Ip, E., Hughes, J.N., et al. (2017). NAD Deficiency, Congenital Malformations, and Niacin Supplementation. N Engl J Med 377, 544-552.

Sobol, R.W., Prasad, R., Evenski, A., Baker, A., Yang, X.P., Horton, J.K., and Wilson, S.H. (2000). The lyase activity of the DNA repair protein beta-polymerase protects from DNA-damage-induced cytotoxicity. Nature 405, 807-810.

Srivastava, D.K., Berg, B.J., Prasad, R., Molina, J.T., Beard, W.A., Tomkinson, A.E., and Wilson, S.H. (1998). Mammalian abasic site base excision repair. Identification of the reaction sequence and rate-determining steps. Journal of Biological Chemistry 273, 21203-21209.

Svilar, D., Goellner, E.M., Almeida, K.H., and Sobol, R.W. (2011). Base excision repair and lesion-dependent subpathways for repair of oxidative DNA damage. Antioxid Redox Signal 14, 2491-2507.

Tang, J.B., Goellner, E.M., Wang, X.H., Trivedi, R.N., St Croix, C.M., Jelezcova, E., Svilar, D., Brown, A.R., and Sobol, R.W. (2010). Bioenergetic metabolites regulate base excision repair-dependent cell death in response to DNA damage. Mol Cancer Res 8, 67-79. 
Teloni, F., and Altmeyer, M. (2016). Readers of poly(ADP-ribose): designed to be fit for purpose. Nucleic Acids Res 44, 993-1006.

Tian, X., Firsanov, D., Zhang, Z., Cheng, Y., Luo, L., Tombline, G., Tan, R., Simon, M., Henderson, S., Steffan, J., et al. (2019). SIRT6 Is Responsible for More Efficient DNA Double-Strand Break Repair in Long-Lived Species. Cell 177, 622-638 e622.

Uhlen, M., Zhang, C., Lee, S., Sjostedt, E., Fagerberg, L., Bidkhori, G., Benfeitas, R., Arif, M., Liu, Z., Edfors, F., et al. (2017). A pathology atlas of the human cancer transcriptome. Science 357.

Wang, Z., Michaud, G.A., Cheng, Z., Zhang, Y., Hinds, T.R., Fan, E., Cong, F., and Xu, W. (2012). Recognition of the iso-ADP-ribose moiety in poly(ADP-ribose) by WWE domains suggests a general mechanism for poly(ADP-ribosyl)ation-dependent ubiquitination. Genes Dev 26, 235-240.

Wilk, A., Hayat, F., Cunningham, R., Li, J., Garavaglia, S., Zamani, L., Ferraris, D.M., Sykora, P., Andrews, J., Clark, J., et al. (2020). Extracellular NAD(+) enhances PARPdependent DNA repair capacity independently of CD73 activity. Sci Rep 10, 651.

Wilson, D.M., 3rd, and Barsky, D. (2001). The major human abasic endonuclease: formation, consequences and repair of abasic lesions in DNA. Mutat Res 485, 283-307.

Yaku, K., Okabe, K., Hikosaka, K., and Nakagawa, T. (2018). NAD Metabolism in Cancer Therapeutics. Frontiers in oncology 8, 622.

Yang, Y., Mohammed, F.S., Zhang, N., and Sauve, A.A. (2019). Dihydronicotinamide riboside is a potent $\mathrm{NAD}(+)$ concentration enhancer in vitro and in vivo. J Biol Chem 294, 9295-9307.

Yang, Y., Zhang, N., Zhang, G., and Sauve, A.A. (2020). NRH salvage and conversion to $\mathrm{NAD}+$ requires NRH kinase activity by adenosine kinase. Nature Metabolism 2, 364-379. 


\section{FIGURE LEGENDS}

Figure 1: Laser-induced micro-irradiation (UVA-355nm) of Pol $\beta$, XRCC1 and ReaIPAR.
A) Current model for Pol $\beta / X R C C 1 / P A R$ complex formation.
B) Recruitment of EGFP-Pol $\beta$ to sites of laser micro-irradiation $(355 \mathrm{~nm})$ in U2OS cells, $\mathrm{n} \geq 35$. Error bars indicate standard error of the mean.

C) Recruitment of XRCC1-EGFP to sites of laser micro-irradiation (355nm) in U2OS cells, $\mathrm{n} \geq 35$.

D) Model of RealPAR's mode of action. RealPAR contains a poly(ADP-ribose) (PAR) binding motif fused to EGFP. Upon micro-irradiation, RealPAR binds to the iso-ADPribose moiety (shown in red) of PAR formed at sites of DNA damage.

E) Recruitment of RealPAR to sites of laser micro-irradiation (355nm) in U2OS cells, $\mathrm{n} \geq 35$.

F) Recruitment of RealPAR to sites of laser micro-irradiation (355nm) in A549 cells, $\mathrm{n} \geq 35$. A single point mutant (Y107A) in RealPAR's PAR binding motif prevented focal recruitment.

G) Inhibition of PARP or PARG alters RealPAR recruitment to sites of laser microirradiation in A549 cells, $n \geq 35$. PARP inhibition, using velipirab (ABT-888, 10 $\mu \mathrm{M}$ ), prevented RealPAR's recruitment, while PARG inhibition (PDD00017273, 10 $\mu \mathrm{M}$ ) retained RealPAR at sites of micro-irradiation by inhibiting the PARG-mediated degradation of PAR.

H) Time to peak recruitment intensity of Pol $\beta, X R C C 1$, and RealPAR in U2OS cells, $n \geq 35$. Pol $\beta$ reached peak recruitment at $30 \pm 2 s$ (mean \pm SEM), XRCC1 at $116 \pm 13 \mathrm{~s}$, and RealPAR at $384 \pm 20$ s. Error bars indicate standard error of the mean.

I) Half-life of recruitment of Pol $\beta, X R C C 1$, and RealPAR in U2OS cells, $n \geq 35$. The halflife of recruitment was $108 \pm 5 \mathrm{~s}$ (mean \pm SEM) for Pol $\beta, 278 \pm 22 \mathrm{~s}$ for XRCC1, and was not detected for RealPAR for 20 minutes post-stimulation in U2OS cells.

J) Serial micro-irradiation of EGFP-Pol $\beta$ in U2OS cells, $n \geq 40$. A $250 \mu$ s imaging interval was used to image single cells with higher temporal resolution than in parallel imaging. 
Results confirm no recruitment peak was observed earlier than the peak observed in the parallel mode results in Figure 1B. Error bars indicate standard error of the mean.

K) Serial micro-irradiation of XRCC1-EGFP in U2OS cells, $n \geq 40$.

L) Serial micro-irradiation of RealPAR in U2OS cells, $n \geq 40$.

See also Figure S1.

Figure 2: Over-expression of EGFP-Pol $\beta$ displays similar recruitment kinetics as endogenously tagged EGFP-Polß.

A) Genomic editing strategy to target the POLB gene on chromosome 8 in A549 cells. The POLB homology region fragment ( 800bp on each side from the transcription start site) was amplified by high-fidelity PCR from A549 genomic DNA. EGFP cDNA was inserted in-frame with the transcriptional start site of POLB, and a silent mutation was placed at the PAM site (AGG to AAG) to prevent re-cleavage by CRISPR/Cas9.

B) Allele sequencing results. Of the three alleles in A549 cells, one was not modified, one was modified with the full length EGFP in frame with POLB exon 1, and one allele displayed a partial $45 \mathrm{bp}$ insertion. The full sequencing results can be found in Supplemental Table $\mathbf{S 2}$.

C) Immunoblot of endogenously tagged A549 cells. Bands were observed at $38.1 \mathrm{kDa}$ (non-modified Pol $\beta$ ) and 70.8kDa (EGFP-Pol $\beta$ ) for the endogenous EGFP-Pol $\beta$ cells. No changes in XRCC1 were observed. PCNA was used for even loading.

D) Spectrally unmixed image of endogenously tagged EGFP-Pol $\beta$ in A549 cells. Each cell displays both nuclear and cytosolic Pol $\beta$. The foci in the image demonstrates EGFP-Pol $\beta$ recruitment to micro-irradiation induced DNA damage.

E) Recruitment of endogenous EGFP-Pol $\beta$ (open circles) and over-expressed EGFPPol $\beta$ (closed circles) to sites of laser micro-irradiation (355nm), $n \geq 35$. Error bars indicate standard error of the mean. 
F) Time to peak recruitment intensity of endogenous EGFP-Pol $\beta$ and over-expressed EGFP-Pol $\beta$ following laser micro-irradiation. No significant difference was observed following a Student's t-test. Error bars indicate standard error of the mean.

G) Half-life of recruitment of endogenous EGFP-Pol $\beta$ and over-expressed EGFP-Pol $\beta$ following laser micro-irradiation. A significant difference $(p<0.05)$ was observed (Student's t-test), with endogenous EGFP-Pol $\beta$ disassembling from the repair complex faster than over-expressed EGFP-Pol $\beta$.

See also Figure S2.

Figure 3: Loss of Polß enzymatic activities does not alter its recruitment kinetics.

A) Recruitment of EGFP-Pol $\beta$, dRP lyase mutant EGFP-Pol $\beta(K 72 A)$, and polymerase mutant EGFP-Pol $\beta(D 256 A)$ in U2OS cells following laser micro-irradiation, $n \geq 35$. Cells retained endogenous Pol $\beta$.

B) Time to peak recruitment intensity of EGFP-Pol $\beta$, EGFP-Pol $\beta(K 72 A)$, and EGFPPol $\beta(D 256 A)$ in U2OS cells following laser micro-irradiation. No significant difference was observed following a one-way ANOVA. Error bars indicate standard error of the mean.

C) Half-life of recruitment of EGFP-Pol $\beta$, EGFP-Pol $\beta(K 72 A)$, and EGFP-Pol $\beta(D 256 A)$ following laser micro-irradiation. No significant difference was observed following a one-way ANOVA.

D) Immunoblot of CRISPR/Cas9-mediated POLB KO in U2OS cells. Two cells lines were generated using two different guide RNAs.

E) Recruitment of EGFP-Pol $\beta$, dRP lyase mutant EGFP-Pol $\beta(K 72 A)$, and polymerase mutant EGFP-Polß(D256A) in U2OS/POLB-KO(1.7) cells, $n \geq 35$. No change in recruitment was observed when endogenous POLB was knocked out.

F) Recruitment of EGFP-Pol $\beta$ and dRP lyase triple mutant EGFP-Pol $\beta(K 35 A / K 68 A K 72 A)$ in A549/POLB-KO cells following laser micro-irradiation, $n \geq 35$. No change in 
recruitment, as compared to WT, was observed when using the triple mutant in the A549 cell line.

See also Figure S3.

Figure 4: Pol $\beta$ 's recruitment is dependent on XRCC1, while Pol $\beta$ enables XRCC1 complex dissociation.

A) Immunoblot of CRISPR/Cas9-mediated XRCC1-KO in U2OS cells. Expression of PCNA is shown as a loading control. Two cells lines were generated using two different guide RNAs.

B) Recruitment of EGFP-Pol $\beta$ in XRCC1-KO cells, $n \geq 35$. Pol $\beta$ failed to recruit in the absence of XRCC1. Error bars indicate standard error of the mean.

C) Recruitment of EGFP-Pol $\beta$ and XRCC1-binding deficient triple mutant EGFP-Pol $\beta$ (L301R/V303R/V306R) in A549 cells following laser micro-irradiation, $n \geq 35$. Pol $\beta$ triple mutant failed to recruit, even with endogenous XRCC1 expressed.

D) Recruitment of XRCC1-EGFP in U2OS/POLB-KO cells following laser microirradiation, $n \geq 35$. XRCC1 demonstrated the ability to recruit to micro-irradiationinduced DNA damage in the absence of Pol $\beta$, but XRCC1 demonstrated slower disassembly from the repair complex in the absence of Pol $\beta$.

E) Recruitment of XRCC1-EGFP in U2OS/POLB-KO cells with POLB restored, $n \geq 35$. $X R C C 1$ demonstrated slower disassembly from the repair complex in the absence of Pol $\beta$. Re-expression of Pol $\beta$ was able to restore the disassembly of $X R C C 1$ from sites of DNA damage.

F) Recruitment of RealPAR in U2OS/POLB-KO cells, $n \geq 35$. U2OS/POLB-KO cells following laser micro-irradiation demonstrated increased PAR formation in comparison to U2OS cells but no change in PAR degradation in the absence of POLB.

See also Figure S4. 
Figure 5: Pol $\beta$ and XRCC1 complex dynamics are dependent on PAR formation and degradation.

A) Immunoblot of CRISPR/Cas9-mediated PARP1-KO in U2OS cells.

B) Recruitment of EGFP-Pol $\beta$ in U2OS/PARP1-KO cells following laser micro-irradiation, $\mathrm{n} \geq 35$. Pol $\beta$ recruitment was attenuated, in the absence of PARP1. Error bars indicate standard error of the mean.

C) Recruitment of EGFP-Pol $\beta$ in A549 cells following laser micro-irradiation with PARP or PARG inhibition, $n \geq 35$. PARP inhibition $(10 \mu \mathrm{M}$ ABT888) attenuated Pol $\beta$ recruitment, and PARG inhibition (10 $\mu \mathrm{M}$ PDD00017273) enhanced Pol $\beta$ 's peak recruitment intensity and prolonged focal recruitment at sites of micro-irradiation.

D) Recruitment of XRCC1-EGFP in A549 cells following laser micro-irradiation with following $P A R P$ or $P A R G$ inhibition, $n \geq 35$. PARP inhibition attenuated $X R C C 1$ recruitment, and PARG inhibition enhanced XRCC1's peak recruitment intensity and prolonged focal recruitment at sites of micro-irradiation.

See also Figure S5.

Figure 6: Pol $\beta$ and XRCC1 complex dynamics are regulated by $\mathrm{NAD}^{+}$bioavailability.

A) $\mathrm{NAD}^{+}$concentrations in U2OS cells following treatment with the NAMPT-inhibitor FK866 $(10 \mu \mathrm{M}, 24$ hours). FK866 reduced NAD+ concentrations to $23 \%$ of control ( $p<0.01$; Student's t-test). Graphs depict mean and standard error of the mean.

B) Time course of $\mathrm{NAD}^{+}$concentrations in U2OS cells following NRH treatment $(100 \mu \mathrm{M})$. $\mathrm{NRH}$ increased $\mathrm{NAD}^{+}$concentrations by $850 \%$ in U2OS cells following 4 hours of treatment ( $p<0.01$; one-way ANOVA and a Tukey post-hoc test). NRH did not enhance $\mathrm{NAD}^{+}$in A549 cells. Graphs depict mean and standard error of the mean. 
C) Immunoblots revealing PAR formation in U2OS cells following a combination of $\mathrm{H}_{2} \mathrm{O}_{2}$, $\mathrm{NRH}$, FK866, or ABT-888 treatment. PAR formation was stimulated using $\mathrm{H}_{2} \mathrm{O}_{2}$ $(100 \mu \mathrm{M}$ or $300 \mu \mathrm{M})$. NRH enhanced PARylation following $\mathrm{H}_{2} \mathrm{O}_{2}$ treatment, while ABT888 was able to block the effect. Similarly, FK866 pre-treatment attenuated PAR formation upon $\mathrm{H}_{2} \mathrm{O}_{2}$ treatment.

D) Recruitment of EGFP-Pol $\beta$ to sites of laser micro-irradiation (355nm) in U2OS cells following $\mathrm{NRH}$ treatment, $\mathrm{n} \geq 35$. Pol $\beta$ peak recruitment intensity was enhanced (45\%) following 4 hours NRH pre-treatment $(100 \mu \mathrm{M})$. Error bars indicate standard error of the mean.

E) Recruitment of XRCC1-EGFP to sites of laser micro-irradiation (355nm) in U2OS cells following $\mathrm{NRH}$ treatment, $\mathrm{n} \geq 35$. XRCC1 peak recruitment intensity was enhanced (94\%) following 4 hours NRH pre-treatment.

F) Recruitment of RealPAR to sites of laser micro-irradiation (355nm) in U2OS cells following $\mathrm{NRH}$ treatment, $\mathrm{n} \geq 35$. RealPAR peak recruitment intensity was enhanced (88\%) following 4 hours NRH pre-treatment.

G) Recruitment of EGFP-Pol $\beta$ to sites of laser micro-irradiation (355nm) in U2OS cells following FK866 treatment $(10 \mu \mathrm{M}), \mathrm{n} \geq 35$. Error bars indicate standard error of the mean.

H) Recruitment of XRCC1-EGFP to sites of laser micro-irradiation (355nm) in U2OS cells following FK866 treatment, $\mathrm{n} \geq 35$.

I) Recruitment of RealPAR to sites of laser micro-irradiation (355nm) in U2OS cells following FK866 treatment, $\mathrm{n} \geq 35$.

See also Figure S6. 
Figure 7: Loss of SIRT6 impairs Pol $\beta$ and XRCC1 complex assembly without altering PAR formation.

A) Immunoblot of CRISPR/Cas9-mediated SIRT6-KO in A549 cells.

B) Recruitment of EGFP-Pol $\beta$ to sites of laser micro-irradiation $(355 \mathrm{~nm})$ in SIRT6-KO cells, $n \geq 35$. Pol $\beta$ recruitment was attenuated in the absence of SIRT6. Error bars indicate standard error of the mean.

C) Recruitment of XRCC1-EGFP to sites of laser micro-irradiation (355nm) in SIRT6-KO cells, $n \geq 35$. XRCC1 recruitment was attenuated in the absence of SIRT6.

D) Recruitment of RealPAR to sites of laser micro-irradiation $(355 \mathrm{~nm})$ in SIRT6-KO cells, $n \geq 35$. RealPAR recruitment was unchanged in the absence of SIRT6.

E) Model of SIRT6 activity on PAR-dependent recruitment of XRCC1 to sites of DNA damage. SIRT6 regulates the ability of XRCC1 to bind to PAR following microirradiation. PAR formation is unchanged in SIRT6-KO cells. The reduction in SIRT6 reduces the recruitment of XRCC1 binding proteins, including Pol $\beta$. 


\title{
Methods
}

\section{Temporal dynamics of base excision / single-strand break repair protein complex assembly and disassembly are modulated by the PARP1/NAD + SIRT6 axis}

\author{
Christopher A. Koczor ${ }^{1,2}$, Kate M. Saville ${ }^{1,2}$, Joel F. Andrews ${ }^{1}$, Jennifer Clark ${ }^{1,2}$, \\ Qingming Fang ${ }^{1,2}$, Jianfeng Li ${ }^{1,2}$, Mikhail V. Makarov ${ }^{1,2}$, Marie Migaud ${ }^{1,2}$ and \\ Robert W. Sobol ${ }^{* 1,2}$
}

\begin{abstract}
Affiliations
${ }^{1}$ Mitchell Cancer Institute, University of South Alabama, Mobile, AL 36604, USA

${ }^{2}$ Department of Pharmacology, College of Medicine, University of South Alabama, Mobile, AL 36604, USA

*Correspondence:

Robert W. Sobol, PhD; Mitchell Cancer Institute, University of South Alabama, 1660 Springhill Avenue, Mobile, AL 36604, USA.

E-mail: rwsobol@southalabama.edu
\end{abstract}

\author{
Key Resources Table \\ Contact for reagent and resource sharing \\ Experimental Model and Subject Details \\ Method Details
}




\begin{tabular}{|c|c|c|}
\hline REAGENT or RESOURCE & SOURCE & IDENTIFIER \\
\hline \multicolumn{3}{|l|}{ Antibodies (dilution) - Immunoblot } \\
\hline Rabbit anti-XRCC1 (1:2500) & Bethyl Laboratories & Cat\# A300-065A \\
\hline Mouse anti-Pol $\beta$ (Clone 61) (1:1000) & $\begin{array}{l}\text { Thermo Fisher } \\
\text { Scientific }\end{array}$ & Cat\# MA5-12066 \\
\hline Mouse anti-PARP1 (1:1000) & Santa Cruz & Cat\# sc-8007 \\
\hline Rabbit anti-C6orf130 (TARG) (1:1000) & $\begin{array}{l}\text { Thermo Fisher } \\
\text { Scientific }\end{array}$ & Cat\# 25249-1-AP \\
\hline Rabbit anti-SIRT6 (1:1000) & Novus Biologicals & Cat\# NB100-2523 \\
\hline Mouse anti-PCNA (1:2500) & $\begin{array}{l}\text { Santa Cruz } \\
\text { Biotechnology }\end{array}$ & Cat\# sc-56 \\
\hline Mouse anti-PAR (10H) (1:1000) & $\begin{array}{l}\text { Generous gift from } \\
\text { Mathias Ziegler } \\
\text { (University of } \\
\text { Bergen, Norway) }\end{array}$ & Clone $10 \mathrm{H}$ \\
\hline Mouse anti-beta actin (1:2500) & Sigma & Cat\# A5441 \\
\hline Rabbit anti-beta actin $(1: 1000)$ & $\begin{array}{l}\text { Santa Cruz } \\
\text { Biotechnology }\end{array}$ & Cat\# ab8227 \\
\hline Rabbit anti- $\gamma \mathrm{H} 2 \mathrm{AX}(1: 1000)$ & Trevigen & 2305-PC-100 \\
\hline Immun-Star Goat anti-mouse-HRP conjugate (1:2500) & Bio-Rad & Cat\# 170-5047 \\
\hline Immun-Star Goat anti-rabbit-HRP conjugate (1:2500) & Bio-Rad & Cat\# 170-5046 \\
\hline \multicolumn{3}{|l|}{ Antibodies (dilution) - Immunofluorescence } \\
\hline Mouse anti-PAR $(10 \mathrm{H})(1: 200)$ & $\begin{array}{l}\text { Generous gift from } \\
\text { Mathias Ziegler } \\
\text { (University of } \\
\text { Bergen, Norway) }\end{array}$ & Clone $10 \mathrm{H}$ \\
\hline $\begin{array}{l}\text { Goat anti-mouse secondary antibody, Alexa Fluor } 568 \\
(1: 1000)\end{array}$ & $\begin{array}{l}\text { Thermo Fisher } \\
\text { Scientific }\end{array}$ & Cat\# A11031 \\
\hline \multicolumn{3}{|l|}{ Reagents } \\
\hline Fetal bovine serum & Bio-Techne & Cat\# S11150 \\
\hline Heat-inactivated fetal bovine serum & Bio-Techne & Cat\# S11150H \\
\hline Penicillin/streptomycin & $\begin{array}{l}\text { Thermo Fisher } \\
\text { Scientific }\end{array}$ & Cat\# 15140-122 \\
\hline DMEM & Corning & Cat\# 15-017-CV \\
\hline L-glutamine & $\begin{array}{l}\text { Thermo Fisher } \\
\text { Scientific }\end{array}$ & Cat\# 25030-081 \\
\hline Dimethyl Sulfoxide & $\begin{array}{l}\text { Thermo Fisher } \\
\text { Scientific }\end{array}$ & Cat\# BP231-1 \\
\hline Puromycin & Sigma-Aldrich & Cat\# P9620-10ml \\
\hline Hygromycin & $\begin{array}{l}\text { Thermo Fisher } \\
\text { Scientific }\end{array}$ & Cat\# 10687010 \\
\hline Trypsin-EDTA & $\begin{array}{l}\text { Thermo Fisher } \\
\text { Scientific }\end{array}$ & Cat\# 25200-056 \\
\hline $0.2 \mu \mathrm{M}$ PVDF & Bio-Rad & Cat\# 162-0174 \\
\hline $0.45 \mu \mathrm{M}$ nitrocellulose & Bio-Rad & Cat\# 162-0115 \\
\hline $0.45 \mu \mathrm{M}$ Durapore Steriflip Filters & Sigma-Aldrich & Cat\# SE1M003M00 \\
\hline Polybrene & Sigma-Aldrich & Cat\# 107689 \\
\hline Protease inhibitor cocktail tablets & $\begin{array}{l}\text { Thermo Fisher } \\
\text { Scientific }\end{array}$ & Cat\# 88666 \\
\hline
\end{tabular}




\begin{tabular}{|c|c|c|}
\hline Blotting grade non-fat dry milk & Bio-Rad & Cat\# 170-6404 \\
\hline Nupage $4-12 \%$ Bis-Tris gel & Invitrogen & Cat\# NP0323BOX \\
\hline Clarity Western ECL Substrate & Bio-Rad & Cat\# 1705060 \\
\hline SuperSignal West Femto Maximum Sensitivity Substrate & $\begin{array}{l}\text { Thermo Fisher } \\
\text { Scientific }\end{array}$ & Cat\# 34095 \\
\hline DC protein assay kit & Bio-Rad & Cat\# 5000112 \\
\hline ABT-888 (Velipirab) & Selleckchem & Cat\# S1004 \\
\hline PDD00017273 & Sigma-Aldrich & SML1781 \\
\hline FK866 & $\begin{array}{l}\text { National Institute of } \\
\text { Mental Health } \\
\text { Chemical Synthesis } \\
\text { and Drug Supply } \\
\text { Program (Bethesda, } \\
\text { MD). }\end{array}$ & \\
\hline $\begin{array}{l}\text { 1-[(2R,3R,4S,5R)-3,4-Dihydroxy-5- } \\
\text { (hydroxymethyl)tetrahydrofuran-2-yl]-4H-pyridine-3- } \\
\text { carboxamide (NRH) }\end{array}$ & Marie Migaud & $\begin{array}{l}\text { (Giroud-Gerbetant et } \\
\text { al., 2019) }\end{array}$ \\
\hline QIAprep Spin Miniprep Kit & Qiagen & Cat\# 27106 \\
\hline QIAGEN DNeasy Blood and Tissue Kit & Qiagen & Cat\# 69504 \\
\hline Hydrogen Peroxide (9.8M) & Sigma-Aldrich & Cat\# H1009 \\
\hline Hoechst 33342 & $\begin{array}{l}\text { Thermo Fisher } \\
\text { Scientific }\end{array}$ & Cat\# 62249 \\
\hline Formaldehyde solution (37\%) & $\begin{array}{l}\text { Thermo Fisher } \\
\text { Scientific }\end{array}$ & Cat\# BP531-500 \\
\hline Normal Goat Serum (lyophilized) & $\begin{array}{l}\text { Thermo Fisher } \\
\text { Scientific }\end{array}$ & Cat\# NC9660079 \\
\hline NucBlue Fixed Cell Stain Ready Probes & $\begin{array}{l}\text { Thermo Fisher } \\
\text { Scientific }\end{array}$ & Cat\# R37606 \\
\hline Alexa Fluor 647 Phalloidin & $\begin{array}{l}\text { Thermo Fisher } \\
\text { Scientific }\end{array}$ & Cat\# A22287 \\
\hline Alt-R CRISPR S.p. Cas9 Nuclease 3NLS & IDT & Cat\# 1074182 \\
\hline Alt-R CRISPR-Cas9 tracrRNA & IDT & Cat\# 1072533 \\
\hline Opti-MEM $^{\mathrm{TM}}$ I Reduced Serum Medium & $\begin{array}{l}\text { Thermo Fisher } \\
\text { Scientific }\end{array}$ & Cat\# 31985062 \\
\hline Lipofectamine $^{\mathrm{TM}}$ RNAiMAX Transfection Reagent & $\begin{array}{l}\text { Thermo Fisher } \\
\text { Scientific }\end{array}$ & Cat\# 13778075 \\
\hline QuikChange II XL Site-directed Mutagenesis Kit & Agilent & Cat\# 200521 \\
\hline TransIT-X2 Transfection Reagent & Mirus Bio & Cat\# MIR 6005 \\
\hline EnzyChrom ${ }^{\mathrm{TM}} \mathrm{NAD}^{+} / \mathrm{NADH}$ assay kit & BioAssay Systems & EZND-100 \\
\hline \multicolumn{3}{|l|}{ Bacterial and virus strains } \\
\hline One Shot ${ }^{\text {TM }}$ STBL 3 Chemically Competent $E$. coli & $\begin{array}{l}\text { Thermo Fisher } \\
\text { Scientific }\end{array}$ & Cat\# C737303 \\
\hline \multicolumn{3}{|l|}{ Cell line growth media } \\
\hline $\begin{array}{l}\text { DMEM with } 10 \% \text { FBS, } 80 u \text { Penicillin/80 } \mu \mathrm{g} \text { Streptomycin } \\
2 \mathrm{mM} \text { L-Glutamine }\end{array}$ & This study & Media \#1 \\
\hline Media \#1 supplemented with Puromycin $(1.0 \mu \mathrm{g} / \mathrm{ml})$ & This study & Media \#2 \\
\hline Media \#1 supplemented with Hygromycin $(200 \mu \mathrm{g} / \mathrm{ml})$ & This study & Media \#3 \\
\hline $\begin{array}{l}\text { Media \#1 supplemented with Puromycin }(1.0 \mu \mathrm{g} / \mathrm{ml}) \text { and } \\
\text { Hygromycin B }(200 \mu \mathrm{g} / \mathrm{ml})\end{array}$ & This study & Media \#4 \\
\hline
\end{tabular}




\begin{tabular}{|c|c|c|}
\hline Cell lines (description) & & \\
\hline $\begin{array}{l}\text { U2OS } \\
\text { (Human osteosarcoma tumor cell line) }\end{array}$ & ATCC & Media \#1 \\
\hline $\begin{array}{l}\text { U2OS/Cas } 9 \\
\text { (U2OS cells expressing Cas9 and a control gRNA; Sobol lab stock } \\
\text { 2014) }\end{array}$ & This study & Media \#2 \\
\hline $\begin{array}{l}\text { U2OS/POLB-KO-1.7 } \\
\text { (U2OS cells expressing Cas9 and a POLB gRNA1; Sobol lab stock 2034) }\end{array}$ & This study & Media \#2 \\
\hline $\begin{array}{l}\text { U2OS/POLBKO-2.1 } \\
\text { (U2OS cells expressing Cas9 and a POLB gRNA2; Sobol lab stock 1962) }\end{array}$ & This study & Media \#2 \\
\hline $\begin{array}{l}\text { U2OS/XRCC1-KO-Exon2 } \\
\text { (U2OS cells expressing Cas9 and a XRCC1 gRNA1; Sobol lab stock } \\
\text { 1886) }\end{array}$ & This study & Media \#2 \\
\hline $\begin{array}{l}\text { U2OS/XRCC1-KO-EXon3 } \\
\text { (U2OS cells expressing Cas9 and a XRCC1 gRNA2; Sobol lab stock } \\
\text { 1887) }\end{array}$ & This study & Media \#2 \\
\hline $\begin{array}{l}\text { U2OS/PARP1-KO } \\
\text { (U2OS cells expressing Cas9 and a PARP1 gRNA1; Sobol lab stock } \\
\text { 1864) }\end{array}$ & This study & Media \#2 \\
\hline $\begin{array}{l}\text { U2OS/EGFP-POLB } \\
\text { (U2OS cells expressing EGFP fused to the N-terminus of POLB; Sobol } \\
\text { lab stock 1573) }\end{array}$ & This study & Media \#3 \\
\hline $\begin{array}{l}\text { U2OS/EGFP-POLB(K72A) } \\
\text { (U2OS cells expressing EGFP fused to the N-terminus of POLB } \\
\text { containing a K72A mutation; Sobol lab stock 1617) }\end{array}$ & This study & Media \#3 \\
\hline $\begin{array}{l}\text { U2OS/EGFP-POLB(D256A) } \\
\text { (U2OS cells expressing EGFP fused to the N-terminus of POLB } \\
\text { containing a D256A mutation; Sobol lab stock 1647) }\end{array}$ & This study & Media \#3 \\
\hline $\begin{array}{l}\text { U2OS/XRCC1-EGFP } \\
\text { (U2OS cells expressing EGFP fused to the C-terminus of XRCC1; Sobol } \\
\text { lab stock 1726) }\end{array}$ & This study & Media \#3 \\
\hline $\begin{array}{l}\text { U2OS/RealPAR } \\
\text { (U2OS cells expressing RealPAR; Sobol lab stock 1727) }\end{array}$ & This study & Media \#3 \\
\hline $\begin{array}{l}\text { U2OS/Apple-53BP1-trunc } \\
\text { (U2OS cells expressing Apple fused to a truncated 53BP1 containing } \\
\text { amino acids 1220-1709; Sobol lab stock 1343) }\end{array}$ & This study & Media \#2 \\
\hline $\begin{array}{l}\text { U2OS/Cas9/EGFP-POLB-PAMmut } \\
\text { (U2OS cells expressing: 1) Cas9 and a control gRNA1; Sobol lab stock } \\
\text { 2014, and 2) EGFP fused to the N-terminus of POLB with mutation G24A } \\
\text { to prevent Cas9 digestion; Sobol lab stock 1718) }\end{array}$ & This study & Media \#4 \\
\hline $\begin{array}{l}\text { U2OS/Cas9/EGFP-POLB(K72A)-PAMmut } \\
\text { (U2OS cells expressing: 1) Cas9 and a control gRNA1; Sobol lab stock } \\
\text { 2014, and 2) EGFP fused to the N-terminus of POLB with mutations } \\
\text { G24A to prevent Cas9 digestion and K72A; Sobol lab stock 1719) }\end{array}$ & This study & Media \#4 \\
\hline $\begin{array}{l}\text { U2OS/Cas9/EGFP-POLB(D256A)-PAMmut } \\
\text { (U2OS cells expressing: 1) Cas9 and a control gRNA1; Sobol lab stock } \\
\text { 2014, and 2) EGFP fused to the N-terminus of POLB with mutations } \\
\text { G24A to prevent Cas9 digestion and D256A; Sobol lab stock 1720) }\end{array}$ & This study & Media \#4 \\
\hline $\begin{array}{l}\text { U2OS/POLB-KO-1.7/EGFP-POLB-PAMmut } \\
\text { (U2OS cells expressing: 1) Cas9 and POLB gRNA1; Sobol lab stock } \\
\text { 2034, and 2) EGFP fused to the N-terminus of POLB with mutation G24A } \\
\text { to prevent Cas9 digestion; Sobol lab stock 1718) }\end{array}$ & This study & Media \#4 \\
\hline $\begin{array}{l}\text { U2OS/POLB-KO-1.7/EGFP-POLB(K72A)-PAMmut } \\
\text { (U2OS cells expressing: 1) Cas9 and a POLB gRNA1; Sobol lab stock } \\
\text { 2034, and 2) EGFP fused to the N-terminus of POLB with mutation G24A } \\
\text { to prevent Cas9 digestion and K72A; Sobol lab stock 1719) }\end{array}$ & This study & Media \#4 \\
\hline $\begin{array}{l}\text { U2OS/POLB-KO-1.7/EGFP-POLB(D256A)-PAMmut } \\
\text { (U2OS cells expressing: 1) Cas9 and a POLB gRNA1; Sobol lab stock } \\
\text { 2034, and 2) EGFP fused to the N-terminus of POLB with mutation G24A } \\
\text { to prevent Cas9 digestion and D256A; Sobol lab stock 1720) }\end{array}$ & This study & Media \#4 \\
\hline
\end{tabular}




\begin{tabular}{|c|c|c|}
\hline $\begin{array}{l}\text { U2OS/XRCC1-KO-Exon2/EGFP-POLB } \\
\text { (U2OS cells expressing:1) Cas9 and a XRCC1 gRNA1; Sobol lab stock } \\
\text { 1886, and 2) EGFP fused to the N-terminus of POLB; Sobol lab stock } \\
\text { 1573) }\end{array}$ & This study & Media \#4 \\
\hline $\begin{array}{l}\text { U2OS/XRCC1-KO-Exon3/EGFP-POLB } \\
\text { (U2OS cells expressing:1) Cas9 and a XRCC1 gRNA2; Sobol lab stock } \\
\text { 1887, and 2) EGFP fused to the N-terminus of POLB; Sobol lab stock } \\
\text { 1573) }\end{array}$ & This study & Media \#4 \\
\hline $\begin{array}{l}\text { U2OS/PARP1-KO/EGFP-POLB } \\
\text { (U2OS cells expressing: 1) Cas9 and a PARP1 gRNA; Sobol lab stock } \\
\text { 1864, and 2) EGFP fused to the N-terminus of POLB; Sobol lab stock } \\
\text { 1573) }\end{array}$ & This study & Media \#4 \\
\hline $\begin{array}{l}\text { A549 } \\
\text { (Human adenocarcinoma tumor cell line) }\end{array}$ & ATCC & Media \#1 \\
\hline $\begin{array}{l}\text { A549/EGFP-POLB } \\
\text { (A549 cells expressing EGFP fused to the N-terminus of POLB; Sobol } \\
\text { lab stock 1573) }\end{array}$ & This study & Media \#3 \\
\hline $\begin{array}{l}\text { A549/XRCC1-EGFP } \\
\text { (A549 cells expressing EGFP fused to the C-terminus of XRCC1; Sobol } \\
\text { lab stock 1726) }\end{array}$ & This study & Media \#3 \\
\hline $\begin{array}{l}\text { A549/RealPAR } \\
\text { (A549 cells expressing RealPAR; Sobol lab stock 1727) }\end{array}$ & This study & Media \#3 \\
\hline $\begin{array}{l}\text { A549/RealPAR-negative } \\
\text { (A549 cells expressing RealPAR with a Y107A mutation; Sobol lab stock } \\
\text { 1806) }\end{array}$ & This study & Media \#3 \\
\hline $\begin{array}{l}\text { A549/Cas } 9 \\
\text { (A549 cells expressing Cas9 and a control gRNA; Sobol lab stock 2014) }\end{array}$ & This study & Media \#2 \\
\hline $\begin{array}{l}\text { A549/TARG-KO-1.3 } \\
\text { (A549 cells expressing Cas9 and TARG-KO gRNA1, cell clone \#3) }\end{array}$ & This study & Media \#2 \\
\hline $\begin{array}{l}\text { A549/TARG-KO-1.6 } \\
\text { (A549 cells expressing Cas9 and TARG-KO gRNA1, cell clone \#6) }\end{array}$ & This study & Media \#2 \\
\hline $\begin{array}{l}\text { A549/Cas9/EGFP-POLB } \\
\text { (A549 cells expressing: 1) Cas9 and a control gRNA1; Sobol lab stock } \\
\text { 2014, and 2) EGFP fused to the N-terminus of POLB; Sobol lab stock } \\
\text { 1573) }\end{array}$ & This study & Media \#4 \\
\hline $\begin{array}{l}\text { A549/TARG-KO-1.3/EGFP-POLB } \\
\text { (A549 cells expressing: 1) Cas9 and TARG-KO gRNA1, and 2) EGFP } \\
\text { fused to the N-terminus of POLB; Sobol lab stock 1573) }\end{array}$ & This study & Media \#4 \\
\hline $\begin{array}{l}\text { A549/TARG-KO-1.6/EGFP-POLB } \\
\text { (A549 cells expressing: 1) Cas9 and TARG-KO gRNA1, and 2) EGFP } \\
\text { fused to the N-terminus of POLB-Sobol lab stock 1573) }\end{array}$ & This study & Media \#4 \\
\hline $\begin{array}{l}\text { A549/SIRT6-KO-1.4 } \\
\text { (A549 cells expressing Cas9 and SIRT6-KO gRNA1, cell clone \#4) }\end{array}$ & This study & Media \#2 \\
\hline $\begin{array}{l}\text { A549/SIRT6-KO-1.4/EGFP-POLB } \\
\text { (A549 cells expressing: 1) Cas9 and SIRT6-KO gRNA1, and 2) EGFP } \\
\text { fused to the N-terminus of POLB; Sobol lab stock 1573) }\end{array}$ & This study & Media \#4 \\
\hline $\begin{array}{l}\text { A549/Cas9/XRCC1-mCherry } \\
\text { (A549 cells expressing: 1) Cas9 and a control gRNA1; Sobol lab stock } \\
\text { 2014, and 2) mCherry fused to the C-terminus of XRCC1; Sobol lab } \\
\text { stock 1494) }\end{array}$ & This study & Media \#4 \\
\hline $\begin{array}{l}\text { A549/SIRT6-KO-1.4/XRCC1-mCherry } \\
\text { (A549 cells expressing: 1) Cas9 and SIRT6-KO gRNA1, and 2) mCherry } \\
\text { fused to the C-terminus of XRCC1; Sobol lab stock 1494) }\end{array}$ & This study & Media \#4 \\
\hline $\begin{array}{l}\text { A549/Cas9/RealPAR } \\
\text { (A549 cells expressing: 1) Cas9 and a control gRNA1; Sobol lab stock } \\
\text { 2014, and 2) RealPAR; Sobol lab stock 1727) }\end{array}$ & This study & Media \#4 \\
\hline $\begin{array}{l}\text { A549/SIRT6-KO-1.4/RealPAR } \\
\text { (A549 cells expressing: 1) Cas9 and SIRT6-KO gRNA1, and 2) RealPAR; } \\
\text { Sobol lab stock 1727) }\end{array}$ & This study & Media \#4 \\
\hline $\begin{array}{l}\text { A549/EGFP-POLB(endogenous) } \\
\text { (A549 cells encoding an endogenously expressed EGFP-POLB) }\end{array}$ & This study & Media \#1 \\
\hline
\end{tabular}




\begin{tabular}{|c|c|c|}
\hline \multicolumn{3}{|l|}{ Oligoribonucleotides } \\
\hline $\begin{array}{l}\text { POLB gRNA: rG/rA/rG/rC/rA/rA/rA/rC/rG/rG/rA/rA/rG/rG/ } \\
\text { rC/rG/rC/rC/rG/rC }\end{array}$ & IDT & POLB gRNA\#1 \\
\hline \multicolumn{3}{|l|}{ Oligodeoxynucleotides - Sequencing } \\
\hline $\begin{array}{l}\text { pUC19-POLBHR-EGFP Sequencing Primer } 1 \\
\text { 5'-GTTGTGTGGAATTGTGAGCGG }\end{array}$ & $\begin{array}{l}\text { Thermo Fisher } \\
\text { Scientific }\end{array}$ & Sobol lab stock 1353 \\
\hline $\begin{array}{l}\text { pUC19-POLBHR-EGFP Sequencing Primer } 2 \\
\text { 5'-GTCAAAACTCCAGGTCTTCCC }\end{array}$ & $\begin{array}{l}\text { Thermo Fisher } \\
\text { Scientific }\end{array}$ & Sobol lab stock 1354 \\
\hline $\begin{array}{l}\text { pUC19-POLBHR-EGFP Sequencing Primer } 3 \\
\text { 5'-GACTTCTTCAAGTCCGCCATG }\end{array}$ & $\begin{array}{l}\text { Thermo Fisher } \\
\text { Scientific }\end{array}$ & Sobol lab stock 1355 \\
\hline $\begin{array}{l}\text { pUC19-POLBHR-EGFP Sequencing Primer } 4 \\
\text { 5'-CACACCGACAGTCCAGTGGGT }\end{array}$ & $\begin{array}{l}\text { Thermo Fisher } \\
\text { Scientific }\end{array}$ & Sobol lab stock 1356 \\
\hline $\begin{array}{l}\text { pUC19-POLBHR-EGFP Sequencing Primer } 5 \\
\text { 5'-TAACCGTAATGAAAGACAGCGG }\end{array}$ & $\begin{array}{l}\text { Thermo Fisher } \\
\text { Scientific }\end{array}$ & Sobol lab stock 1357 \\
\hline $\begin{array}{l}\text { POLBHR-EGFP Sequencing Primer } 1 \\
\text { 5'-CATGGCGGACTTGAAGAAGTC }\end{array}$ & $\begin{array}{l}\text { Thermo Fisher } \\
\text { Scientific }\end{array}$ & Sobol lab stock 1488 \\
\hline $\begin{array}{l}\text { POLBHR-EGFP Sequencing Primer } 2 \\
\text { 5'-CCAGATTTCTCTACAGCAACTACGTATC }\end{array}$ & $\begin{array}{l}\text { Thermo Fisher } \\
\text { Scientific }\end{array}$ & Sobol lab stock 1509 \\
\hline $\begin{array}{l}\text { POLBHR-EGFP Sequencing Primer } 3 \\
\text { 5'-GGCTAAGGAGTAGAAGCAGGTGGATG }\end{array}$ & $\begin{array}{l}\text { Thermo Fisher } \\
\text { Scientific }\end{array}$ & Sobol lab stock 1460 \\
\hline $\begin{array}{l}\text { PAR binding domain Sequencing Primer } 1 \\
\text { 5'-CTCAAGCCTCAGACAGTGGTTCAAAG }\end{array}$ & $\begin{array}{l}\text { Thermo Fisher } \\
\text { Scientific }\end{array}$ & Sobol lab stock 1511 \\
\hline \multicolumn{3}{|l|}{ Oligodeoxynucleotides - PCR } \\
\hline $\begin{array}{l}\text { POLBHR-Forward } \\
\text { 5'-GCGCGCGCAAGCTTATTGCAGTTCGATATGAACCCAGG }\end{array}$ & $\begin{array}{l}\text { Thermo Fisher } \\
\text { Scientific }\end{array}$ & Sobol lab stock 1427 \\
\hline $\begin{array}{l}\text { POLBHR-Reverse } \\
\text { 5'-ATATATATGAATTACAAGGACAGGATCCCATGAAC }\end{array}$ & $\begin{array}{l}\text { Thermo Fisher } \\
\text { Scientific }\end{array}$ & Sobol lab stock 1428 \\
\hline $\begin{array}{l}\text { EGFP-Sapl-Forward } \\
\text { 5'-GAGAGCTCTTCGGCCATGGTGAGCAAGGGCGAGGAG }\end{array}$ & $\begin{array}{l}\text { Thermo Fisher } \\
\text { Scientific }\end{array}$ & Sobol lab stock 1437 \\
\hline $\begin{array}{l}\text { EGFP-Sapl-Reverse } \\
\text { 5'-CCGGGCTCTTCCCATCTTGTACAGCTCGTCCATGCCG }\end{array}$ & $\begin{array}{l}\text { Thermo Fisher } \\
\text { Scientific }\end{array}$ & Sobol lab stock 1438 \\
\hline $\begin{array}{l}\text { PBD-NterFragmentAmp-For } \\
\text { 5'-GTGGTTACGCGTGCCACCATG }\end{array}$ & $\begin{array}{l}\text { Thermo Fisher } \\
\text { Scientific }\end{array}$ & Sobol lab stock 1485 \\
\hline $\begin{array}{l}\text { PBD-NterFragmentAmp-Rev } \\
\text { 5'-GAAGGAGGATCCACCTCCGC }\end{array}$ & $\begin{array}{l}\text { Thermo Fisher } \\
\text { Scientific }\end{array}$ & Sobol lab stock 1486 \\
\hline $\begin{array}{l}\text { SIRT6-KO Genomic Sequencing Primer-Forward } \\
\text { 5'-ATAGCCTGTGTCCCGCATTT }\end{array}$ & $\begin{array}{l}\text { Thermo Fisher } \\
\text { Scientific }\end{array}$ & Sobol lab stock 1403 \\
\hline $\begin{array}{l}\text { SIRT6-KO Genomic Sequencing Primer-Reverse } \\
\text { 5'-GGGCCATCTTCACCTCGTTT }\end{array}$ & $\begin{array}{l}\text { Thermo Fisher } \\
\text { Scientific }\end{array}$ & Sobol lab stock 1404 \\
\hline $\begin{array}{l}\text { TARG-KO Genomic Sequencing Primer-Forward } \\
\text { 5'-AATGAGAGCGGGTCGAGACA }\end{array}$ & $\begin{array}{l}\text { Thermo Fisher } \\
\text { Scientific }\end{array}$ & Sobol lab stock 1405 \\
\hline $\begin{array}{l}\text { TARG-KO Genomic Sequencing Primer-Reverse } \\
\text { 5'-AGTGGCCCGTAGAAAGTGATG }\end{array}$ & $\begin{array}{l}\text { Thermo Fisher } \\
\text { Scientific }\end{array}$ & Sobol lab stock 1406 \\
\hline \multicolumn{3}{|l|}{$\begin{array}{l}\text { Oligodeoxynucleotides - Site-directed } \\
\text { Mutagenesis }\end{array}$} \\
\hline $\begin{array}{l}\text { Sapl removal from pUC19 SDM-For } \\
\text { 5'-GCGTATTGGGCGCTGTTCCGCTTCCTCGC }\end{array}$ & $\begin{array}{l}\text { Thermo Fisher } \\
\text { Scientific }\end{array}$ & Sobol lab stock 1433 \\
\hline
\end{tabular}




\begin{tabular}{|c|c|c|}
\hline $\begin{array}{l}\text { Sapl removal from pUC19 SDM-Rev } \\
\text { 5'-GCGAGGAAGCGGAACAGCGCCCAATACGC }\end{array}$ & $\begin{array}{l}\text { Thermo Fisher } \\
\text { Scientific }\end{array}$ & Sobol lab stock 1434 \\
\hline $\begin{array}{l}\text { Sapl into POLBHR SDM-For } \\
\text { 5'-GTGCAGGCCGCCGGAAGAGCGCTCTTCCATGAGCAAACGG }\end{array}$ & $\begin{array}{l}\text { Thermo Fisher } \\
\text { Scientific }\end{array}$ & Sobol lab stock 1435 \\
\hline $\begin{array}{l}\text { Sapl into POLBHR SDM-Rev } \\
\text { 5'-CCGTTTGCTCATGGAAGAGCGCTCTTCCGGCGGCCTGCAC }\end{array}$ & $\begin{array}{l}\text { Thermo Fisher } \\
\text { Scientific }\end{array}$ & Sobol lab stock 1436 \\
\hline $\begin{array}{l}\text { POLBHR PAMmut-For } \\
\text { 5'-CGGAAGGCGCCGCAAGAGACTCTCAACGGG }\end{array}$ & $\begin{array}{l}\text { Thermo Fisher } \\
\text { Scientific }\end{array}$ & Sobol lab stock 1431 \\
\hline $\begin{array}{l}\text { POLBHR PAMmut-Rev } \\
\text { 5'-CCCGTTGAGAGTCTCTTGCGGCGCCTTCCG }\end{array}$ & $\begin{array}{l}\text { Thermo Fisher } \\
\text { Scientific }\end{array}$ & Sobol lab stock 1432 \\
\hline \multicolumn{3}{|l|}{ Oligodeoxynucleotides - CRISPR gRNA } \\
\hline $\begin{array}{l}\text { SIRT6 Forward- } \\
\text { 5'-CACCGGATGTCGGTGAATTACGCGG }\end{array}$ & $\begin{array}{l}\text { Thermo Fisher } \\
\text { Scientific }\end{array}$ & Sobol lab stock 1358 \\
\hline $\begin{array}{l}\text { SIRT6 Reverse- } \\
\text { 5'-AAACCCGCGTAATTCACCGACATCC }\end{array}$ & $\begin{array}{l}\text { Thermo Fisher } \\
\text { Scientific }\end{array}$ & Sobol lab stock 1359 \\
\hline $\begin{array}{l}\text { TARG Forward- } \\
\text { 5'-CACCGGGGCTAAAGAGTCTGTTTTC }\end{array}$ & $\begin{array}{l}\text { Thermo Fisher } \\
\text { Scientific }\end{array}$ & Sobol lab stock 1333 \\
\hline $\begin{array}{l}\text { TARG Reverse- } \\
\text { 5'-AAACGAAACAGACTCTTTAGCCCC }\end{array}$ & $\begin{array}{l}\text { Thermo Fisher } \\
\text { Scientific }\end{array}$ & Sobol lab stock 1334 \\
\hline \multicolumn{3}{|l|}{ Target sequences for each gRNA } \\
\hline $\begin{array}{l}\text { Control gRNA: } \\
\text { GCGTACCACACCCGTCGCAT }\end{array}$ & $\begin{array}{l}\text { Generous gift from } \\
\text { Wim Vermeulen } \\
\text { (Erasmus MC, the } \\
\text { Netherlands) }\end{array}$ & Control gRNA \\
\hline $\begin{array}{l}\text { POLB gRNA1: } \\
\text { GAGCAAACGGAAGGCGCCGC }\end{array}$ & (Sykora et al., 2018) & POLB-KO-gRNA1 \\
\hline $\begin{array}{l}\text { POLB gRNA2: } \\
\text { CGCCGCAGGAGACTCTCAAC }\end{array}$ & $\begin{array}{l}\text { Generous gift from } \\
\text { Wim Vermeulen } \\
\text { (Erasmus MC, the } \\
\text { Netherlands) }\end{array}$ & POLB-KO-gRNA2 \\
\hline $\begin{array}{l}\text { XRCC1 gRNA1: } \\
\text { CTGTGCAGAAAATCTTCTCA }\end{array}$ & $\begin{array}{l}\text { Generous gift from } \\
\text { Wim Vermeulen } \\
\text { (Erasmus MC, the } \\
\text { Netherlands) }\end{array}$ & XRCC1-KO-gRNA1 \\
\hline $\begin{array}{l}\text { XRCC1 gRNA2: } \\
\text { AGTGTGGACATTGGGAATGA }\end{array}$ & $\begin{array}{l}\text { Generous gift from } \\
\text { Wim Vermeulen } \\
\text { (Erasmus MC, the } \\
\text { Netherlands) }\end{array}$ & XRCC1-KO-gRNA2 \\
\hline $\begin{array}{l}\text { PARP1 gRNA1: } \\
\text { GTCAAGAAGACAGCGGAAGC }\end{array}$ & $\begin{array}{l}\text { Generous gift from } \\
\text { Wim Vermeulen } \\
\text { (Erasmus MC, the } \\
\text { Netherlands) }\end{array}$ & PARP1-KO-gRNA1 \\
\hline $\begin{array}{l}\text { SIRT6 gRNA1: } \\
\text { GATGTCGGTGAATTACGCGGCGG }\end{array}$ & This study & SIRT6-KO-gRNA1 \\
\hline $\begin{array}{l}\text { TARG gRNA1: } \\
\text { GGGCTAAAGAGTCTGTTTTCGGG }\end{array}$ & This study & TARG-KO-gRNA1 \\
\hline \multicolumn{3}{|l|}{ Vectors (insert description) } \\
\hline $\begin{array}{l}\text { pLentiCRISPRv2 } \\
\text { (Cas9 plus clonable site for gRNA; contains a puromycin resistance } \\
\text { cassette) }\end{array}$ & Addgene (\#52961) & Sobol lab stock 1455 \\
\hline
\end{tabular}


(Cas9 plus control gRNA; contains a puromycin resistance cassette)

pLentiCRISPRv2-POLB-KO-g1

(Cas9 plus POLB gRNA \#1; contains a puromycin resistance cassette)

pLENTI-CRISPR-V2-POLB-KO-g2

(Cas9 plus POLB gRNA \#2; contains a puromycin resistance cassette)

pLENTI-CRISPR-V2-XRCC1-KO-g1

(Cas9 plus XRCC1 gRNA \#1; contains a puromycin resistance cassette)

pLENTI-CRISPR-V2-XRCC1-KO-g2

(Cas9 plus XRCC1 gRNA \#2; contains a puromycin resistance cassette)

pLENTI-CRISPR-V2-PARP1-KO-g1

(Cas9 plus PARP1 gRNA \#1; contains a puromycin resistance cassette)
pLentiCRISPRv2-Con

Generous gift from

Wim Vermeulen

(Erasmus MC, the

Netherlands)

This study

Generous gift from

Wim Vermeulen

(Erasmus MC, the

Netherlands)

Generous gift from

Wim Vermeulen

(Erasmus MC, the

Netherlands)

Generous gift from

Wim Vermeulen

(Erasmus MC, the

Netherlands)

Generous gift from

Wim Vermeulen

(Erasmus MC, the

Netherlands)

pLV-CMV-EGFP-PolB-Hygro

(EGFP fused to the $\mathrm{N}$-terminus of $\mathrm{Pol} \beta$ \& a hygromycin resistance cassette)

pLV-CMV-XRCC1-EGFP-Hygro

(EGFP fused to the C-terminus of XRCC1 \& a hygromycin resistance cassette)

pLV-EF1A-RealPAR-Hygro

(PAR binding domain with EGFP tag \& a hygromycin resistance cassette)

pUC19

pUC19-POLBHR-eGFP

(Homology region \pm 800 bp to the transcription start site of POLB, with EGFP inserted in-frame on the N-terminus of POLB, and a mutation in the PAM site used by POLBKO gRNA1 in POLB exon1)

pLV-Hygro-EF1A-RealPARBackbone

(Expression vector with a BamHI site in frame with a Gly-Ser linker fused to EGFP; serves as the backbone for PAR binding domain incorporation for RealPAR)

pLV-Hygro-EF1A-BRCT-Linker-eGFP

(EGFP fused to the C-terminus of a BRCT domain \& a hygromycin resistance cassette)

pLV-Hygro-EF1A-FHA-Linker-eGFP

(EGFP fused to the C-terminus of a FHA domain \& a hygromycin resistance cassette)

pLV-Hygro-EF1A-KR-Linker-eGFP

(EGFP fused to the C-terminus of a KR domain \& a hygromycin resistance cassette)

pLV-Hygro-EF1A-Macro-Linker-eGFP

(EGFP fused to the C-terminus of a Macrodomain \& a hygromycin resistance cassette)

pLV-Hygro-EF1A-OB-Linker-eGFP

(EGFP fused to the C-terminus of an OB domain \& a hygromycin resistance cassette)

pLV-Hygro-EF1A-PBM-Linker-eGFP

\begin{tabular}{|l|l|}
\hline This study & Sobol lab stock 1573 \\
\hline This study & Sobol lab stock 1726 \\
\hline This study & Sobol lab stock 1727 \\
\hline $\begin{array}{l}\text { New England } \\
\text { Biolabs }\end{array}$ & Cat\# N3041 \\
\hline This study & Sobol lab stock 1717 \\
\hline This study & Sobol lab stock 1749 \\
\hline This study & Sobol lab stock 1762 \\
\hline This study & Sobol lab stock 1763 \\
\hline This study & Sobol lab stock 1764 \\
\hline This study & Sobol lab stock 1765 \\
\hline This study & Sobol lab stock 1766 \\
\hline This study & Sobol lab stock 1767 \\
\hline
\end{tabular}

Sobol lab stock 1886

Sobol lab stock 1864

Sobol lab stock 2014

Sobol lab stock 2034

Sobol lab stock 1962

Sobol lab stock 1887

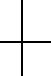

(1)

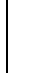




\begin{tabular}{|c|c|c|}
\hline $\begin{array}{l}\text { (EGFP fused to the C-terminus of a PBM domain \& a hygromycin } \\
\text { resistance cassette) }\end{array}$ & & \\
\hline $\begin{array}{l}\text { pLV-Hygro-EF1A-PBZC-Linker-eGFP } \\
\text { (EGFP fused to the C-terminus of an PBZ domain \& a hygromycin } \\
\text { resistance cassette) }\end{array}$ & This study & Sobol lab stock 1768 \\
\hline $\begin{array}{l}\text { pLV-Hygro-EF1A-RG-Linker-eGFP } \\
\text { (EGFP fused to the C-terminus of an RG domain \& a hygromycin } \\
\text { resistance cassette) }\end{array}$ & This study & Sobol lab stock 1769 \\
\hline $\begin{array}{l}\text { pLV-Hygro-EF1A-WWE-Linker-eGFP } \\
\text { (EGFP fused to the C-terminus of a WWE domain \& a hygromycin } \\
\text { resistance cassette) }\end{array}$ & This study & Sobol lab stock 1770 \\
\hline $\begin{array}{l}\text { pLV-EF1A-WWE(Y107A)-EGFP-Hygro } \\
\text { (EGFP fused to the C-terminus of a WWE domain containing a point } \\
\text { mutation to convert Tyr107 to Arg \& a hygromycin resistance cassette) }\end{array}$ & This study & Sobol lab stock 1806 \\
\hline $\begin{array}{l}\text { pLV-CMV-EGFP-PolB-PAMmut-Hygro } \\
\text { (EGFP fused to the N-terminus of POLB containing a mutation in the } \\
\text { PAM site used by POLBKOg1 \& a hygromycin resistance cassette) }\end{array}$ & This study & Sobol lab stock 1718 \\
\hline $\begin{array}{l}\text { pLV-CMV-EGFP-PolB(K72A)-PAMmut-Hygro } \\
\text { (EGFP fused to the N-terminus of POLB containing mutation in Lys72, a } \\
\text { mutation in the PAM site used by POLBKOg1 \& a hygromycin resistance } \\
\text { cassette) }\end{array}$ & This study & Sobol lab stock 1719 \\
\hline $\begin{array}{l}\text { pLV-CMV-EGFP-PolB(D256A)-PAMmut-Hygro- } \\
\text { (EGFP fused to the N-terminus of POLB containing mutation in Asp256, } \\
\text { a mutation in the PAM site used by POLBKOg1 \& a hygromycin } \\
\text { resistance cassette) }\end{array}$ & This study & Sobol lab stock 1720 \\
\hline $\begin{array}{l}\text { pLV-EGFP-PolB(K35A/K68A/K72A)-PAMmut-Hygro- } \\
\text { (EGFP fused to the N-terminus of POLB containing mutations in Lys35, } \\
\text { Lys68, and Lys72, a mutation in the PAM site used by POLB gRNA1 \& a } \\
\text { hygromycin resistance cassette) }\end{array}$ & This study & Sobol lab stock 1833 \\
\hline $\begin{array}{l}\text { pLV-CMV-XRCC1-mCherry-Hygro } \\
\text { (mCherry fused to the C-terminus of XRCC1 \& a hygromycin resistance } \\
\text { cassette) }\end{array}$ & Wilk et al., 2020 & Sobol lab stock 1494 \\
\hline $\begin{array}{l}\text { pLVX-Apple-53BP1trunc-Puro } \\
\text { (Apple fused to the N-terminus of a truncated 53BP1 containing amino } \\
\text { acids 1220-1709) }\end{array}$ & Addgene (\#69531) & Sobol lab stock 1343 \\
\hline $\begin{array}{l}\text { pLV-Hygro-EF1a-XRCC1-EGFP-T2A-myc- } \\
\text { POLB(PAMmut) } \\
\text { (EGFP fused to the C-terminus of XRCC1, linked by T2A to N-terminus } \\
\text { MYC-tagged POLB with a mutation in the PAM site used by POLBKO } \\
\text { gRNA1 \& a hygromycin resistance cassette) }\end{array}$ & This study & Sobol lab stock 1860 \\
\hline \multicolumn{3}{|l|}{ Software and Algorithms } \\
\hline Image J & Image J 1.48v & $\frac{\text { http://imagej.nih.gov/ }}{\text { ijjava 1.6.0_65 }}$ \\
\hline FIJI & $\underline{\text { http://fiji.sc/ }}$ & $\begin{array}{l}\text { (Schindelin et al., } \\
2012 \text { ) }\end{array}$ \\
\hline Adobe Illustrator (for preparation of figures) & Adobe Systems & Version CC \\
\hline GraphPad Prism & GraphPad & $\begin{array}{l}\text { Version } 9 \\
(\text { Mac OS X) }\end{array}$ \\
\hline MIDAS & See below & See below \\
\hline NIS-Elements & Nikon Instruments & Version 4.51 \\
\hline
\end{tabular}




\section{Contact for reagent and resource sharing}

Further information and requests for resources and reagents, including custom analysis scripts, should be directed to and will be fulfilled by Robert W. Sobol (rwsobol@southalabama.edu).

\section{Experimental Model and Subject Details}

The human tumor cell lines A549 and U2OS were obtained from ATCC and are routinely validated by Genetica Cell Line Testing. Human tumor cell lines were modified by lentiviral-mediated expression of the indicated proteins as indicated below and as listed in the Key Resources Table above. In some cases, modified cells were iteratively modified by a second transduction, such as expressing POLB-KO-gRNA in cells followed by expression of EGFP-Polß-PAMMut using lentiviral vectors with different selection makers (Puromycin, Hygromycin). Lentiviral constructs containing EGFP or mCherry fused to POLB, XRCC1 and PAR binding domains were generated for visualization of protein recruitment to sites of laser-induced (micro-irradiation) DNA damage. Genomic modification of A549 cells to introduce EGFP into the endogenous POLB gene was used for visualization of Pol $\beta$ protein recruitment with laser-induced micro-irradiation experiments when evaluating endogenous protein expression levels. Several CRISPR/Cas9 KO vectors were used to establish the effect of the targeted protein loss on the recruitment of EGFP or mCherry-fused DNA repair proteins to sites of laserinduced (micro-irradiation) DNA damage. All parental and modified cell lines were cultured in tissue culture incubators at $37^{\circ} \mathrm{C}, 10 \% \mathrm{CO}_{2}$. 


\section{Method Details}

\section{Chemicals and Reagents}

All chemicals and reagents used for these experiments are listed in the Key Resources Table. FK866 (NIMH \#F-901; IUPAC name: (E)-[4-(1-Benzyoylpiperidin-4-yl)butly]-3(pyridin-3-yl)acrylamide; CAS number: 201034-75-5) was obtained from the National Institute of Mental Health Chemical Synthesis and Drug Supply Program (Bethesda, MD). FK866 was dissolved in DMSO to prepare a stock solution at a concentration of $1 \mathrm{mM}$ and stored at $-80^{\circ} \mathrm{C}$. Dihydronicotinamide Riboside ( $\mathrm{NRH} ; 1-[(2 \mathrm{R}, 3 \mathrm{R}, 4 \mathrm{~S}, 5 \mathrm{R})-3,4-$ Dihydroxy-5-(hydroxymethyl)tetrahydrofuran-2-yl]-4H-pyridine-3-carboxamide) was prepared as described (Giroud-Gerbetant et al., 2019). NRH was dissolved in distilled $\mathrm{H}_{2} \mathrm{O}$ to prepare a stock solution concentration of $100 \mathrm{mM}$ and stored at $-80^{\circ} \mathrm{C}$.

\section{Plasmid and vector development}

Plasmids and lentiviral vectors developed previously or those newly generated for this study, either obtained commercially or from colleagues, are all cited in the Key Resources Table above. Lentiviral vectors were prepared by VectorBuilder Inc. unless specifically stated below. pLV-EGFP-Pol $\beta$-hygro-PAMmut (Sobol lab stock 1718), pLVEGFP-Pol $\beta(K 72 A)$-hygro-PAMmut (Sobol lab stock 1719), and pLV-EGFP-Pol $\beta(D 256 A)-$ hygro-PAMmut (Sobol lab stock 1720) were created by mutating nucleotide G24 in POLB (located in the sequence corresponding to exon 1) to G24A with the Quickchange II XL site-directed mutagenesis kit and the primers listed in the Key Resources Table to generate PAM mutants resistant CRISPR/Cas9 cleavage by POLBKO-gRNA1. Positive clones were selected and plasmids were extracted with the QIAprep Spin Miniprep Kit (Qiagen). Modifications were verified by Sanger sequencing (Eurofins Genomics).

The generation of the pUC19-POLBHR-EGFP insert used for endogenous tagging of the N-terminus of POLB in A549 cells began with modification of commercially available pUC19 plasmid to remove a Sapl restriction site using the QuikChange II XL kit and PCR primers (see Key Resource Table - Sobol lab stock primers 1433 \& 1434). Following clonal selection, the resulting plasmid was then modified to insert a $\sim 1.7 \mathrm{~kb}$ high-fidelity 
PCR-amplified homology region fragment of POLB (including part of exon 1) generated using A549 genomic DNA as the template (Sobol lab stock primers 1427 \& 1428). Following clonal selection, the resulting plasmid was modified to remove the PAM site in POLBHR used by the targeting CRISPR gRNA. Following clonal selection, the plasmid was modified via site-directed mutagenesis to add a Sapl site located at the transcription start site of POLB (Sobol lab stock primers 1435 \& 1436). An oligonucleotide was generated by high-fidelity PCR to contain Sapl restriction fragments on the ends flanking the EGFP cDNA (Sobol lab stock primers 1437 \& 1438). Lastly, the pUC19-POLBHR plasmid was modified to insert the Sapl-EGFP DNA fragment via restriction digestion and ligation at the Sapl site to produce a final pUC19 vector (pUC19-POLBHR-EGFP) with a $\sim 2.5 \mathrm{~kb}$ insert containing $\sim 800 \mathrm{bp}$ upstream homology arm, EGFP in frame with the transcription start site of POLB, a PAM mutation in exon 1 to prevent secondary cleavage by CRISPR/Cas9, and $\sim 800$ bp downstream EGFP-POLB (see Figure 2A). The entire insert was sequenced via Sanger sequencing (Eurofins Genomics) to ensure proper generation.

Generation of constructs containing PAR binding domains (PBD) fused to EGFP began with a commercially purchased lentiviral backbone vector (VectorBuilder Inc.) containing a Gly-Ser linker and EGFP and Mlul and BamHI restriction sites to enable inframe cloning of the PBD (Sobol lab stock 1749). DNA fragments containing each of the PBD sequences were generated by GenScript USA, Inc (see Supplemental Table S1). PBD cDNA was amplified by high-fidelity PCR (Sobol lab stock primers 1485 \& 1486). Each PBD-containing DNA fragment was ligated into the restriction-digested backbone vector and clonally selected. Insertion of the fragment was verified by Sanger sequencing (Eurofins Genomics) (see Supplemental Table S2).

\section{Lentivirus production and cell transduction}

Lentiviral particles were generated by co-transfection of 4 plasmids into 293-FT cells using TransIT-X2 Transfection reagent: the packaging vectors pMD2.g(VSVG), pVSVREV and pMDLg/pRRE together with the appropriate shuttle vectors, as listed in the Key Resources Table above. Forty-eight hours after transfection, lentivirus-containing 
supernatant was collected and passed through $0.45 \mathrm{mM}$ filters to isolate the viral particles as described previously (Fang et al., 2014; Fouquerel et al., 2014).

Lentiviral transduction was performed as follows: cells $\left(1-2 \times 10^{5}\right)$ were seeded into 6-well plates. $24 \mathrm{hrs}$ later, lentiviral particles were mixed with polybrene $(2 \mu \mathrm{g} / \mathrm{ml})$ and added to the cells. Cells were incubated at $32^{\circ} \mathrm{C}$ overnight and then medium with lentiviral particles was removed and replaced with fresh medium. When cells were created to form stable cell lines, cells were cultured for $48 \mathrm{hrs}$ at $37^{\circ} \mathrm{C}$ before selection with antibiotics (puromycin or hygromycin) for 1-2 weeks. When cells were transduced a second time to create a cell expressing a fluorescently-tagged fusion protein in addition to harboring a $\mathrm{KO}$, selection for the first stable cell line was completed and verified prior to initiation of the second transduction. When cells were created for transient expression experiments, cells were cultured for at least $96 \mathrm{hrs}$ at $37^{\circ} \mathrm{C}$ before experimental analysis. All stable cell lines developed and used in this study are listed in the Key Resource Table.

\section{Development of Cas9 expressing and knockout (KO) cells}

We developed U2OS and A549 cell lines with stable knockouts using the one vector CRISPR/Cas9 system (plentiCRISPR-v2; to deliver hSpcas9 and puromycin resistance). The plentiCRISPR-v2 vector was obtained from Addgene (plasmid \#52961). The plentiCRISPR-v2 vectors containing control gRNA, POLB-KO-g2, XRCC1-KO-g1, XRCC1-KO-g2 and PARP1-KO-g1 were gifts from Wim Vermeulen (Erasmus MC, The Netherlands) (Slyskova et al., 2018). To generate plentiCRISPR-v2 containing gRNAs for POLB (using gRNA1), TARG, or SIRT6, we designed the guide RNA (gRNA) using the ChopChop software package (http://chopchop.cbu.uib.no). The resulting gRNAs (and the oligonucleotides used to generate the vectors) are listed in the Key Resources Table. The plasmids were used to generate lentivirus to express Cas9+Control-gRNA or Cas9+KO-gRNA, and U2OS or A549 cells were transduced with lentivirus as indicated above. Cells were maintained in media containing puromycin $(1 \mu \mathrm{g} / \mathrm{ml})$ for 16 days, plated to generate single cell derived colonies, and validated by sequencing and protein immunoblot to confirm the knockout. Details of the technique have been described by us previously (Fang et al., 2019) and earlier by others (Sanjana et al., 2014). 


\section{Generation of A549 cells expressing endogenous EGFP-tagged Pol $\beta$}

Prior to use, the entire 2.5kb POLBHR-EGFP insert utilized for HR-dependent EGFP incorporation was enzymatically cleaved from the pUC19 backbone and gel purified to be used for CRISPR/Cas9 ribonucleotide protein insertion as below. To modify A549 cells to express EGFP-Pol $\beta$ under control of the endogenous POLB promoter, the protocol provided by IDT was followed with minimal changes. First, tracrRNA $(100 \mu \mathrm{M})$ and POLB gRNA1 $(100 \mu \mathrm{M})$ were mixed in room temperature PBS, heated to $95^{\circ} \mathrm{C}$, and cooled slowly to room temperature. Cas9 protein was diluted to a concentration of $1 \mu \mathrm{M}$ in room temperature PBS and then combined with the tracrRNA:POLBgRNA1 duplex to form the ribonucleoprotein complex in OptiMEM at room temperature for 5 minutes. The ribonucleoprotein complex was treated with RNAiMAX in OptiMEM for 20 minutes at room temperature to facilitate cellular delivery. During this time, the $2.5 \mathrm{~kb}$ POLBHR-EGFP DNA fragment was treated with TransIT-X2 in Opti-MEM at room temperature for 15 minutes. Finally, A549 cells were trypsinized and reseeded to $5 \times 10^{5}$ cells in a 6-well dish, followed by addition of the Cas9 ribonucleoprotein complex and the $2.5 \mathrm{~kb}$ POLBHR-EGFP DNA fragment. Cells were incubated for 48 hours, at which time the cells were trypsinized and reseeded into glass-bottom $96-w e l l$ dishes at single-cell density. Single cell clones were grown until visible colonies could be observed. Individual colonies were visualized for EGFP fluorescence using a Nikon A1rsi laser scanning confocal microscope to verify positive EGFP fluorescence. Positive colonies were trypsinized and grown for validation of CRISPR/Cas9 genomic modification of the POLB gene.

In addition to immunoblots and spectral immunofluorescence of EGFP-Pol $\beta$ (methods below), Sanger sequencing was performed to verify correct insertion of EGFP onto the POLB gene. Genomic DNA from A549-POLBHR-EGFP cells was isolated, and the genomic region around the fragment insert site was PCR amplified using high-fidelity PCR and PCR-primers containing HindIII and EcoRI restriction fragments on the ends (Sobol lab stock primers $1427 \&$ 1428). The PCR product was ligated into pUC19, transformed into STBL3 bacteria, and plated to obtain single colonies. Individual bacterial colonies were selected, and plasmids were isolated and sequenced completely across 
the POLBHR region to identify modifications in the POLBHR sequence. All three A549 POLB alleles were sequenced (see Supplemental Figure 2). Following validation, one cell clone was utilized for experimental investigation.

\section{Cell protein extract preparation}

Cell protein extracts (whole cell lysates, WCL) were prepared from cells with different genetic modifications and/or treated with different drugs and for different times as indicated in the text. Cells were seeded into a 60-mm cell culture dish. After reaching 75$80 \%$ confluency, cells were washed twice with cold PBS, collected and lysed with an appropriate volume of $2 x$ clear Laemmli buffer (2\% SDS, $20 \%$ glycerol, $62.5 \mathrm{mmol} / \mathrm{l}$ Tris$\mathrm{HCl}$ pH6.8). Cell lysates were boiled for 10 min and quantified with the DC protein assay kit following the microplate protocol provided by the company (Bio-Rad).

\section{Immunoblot}

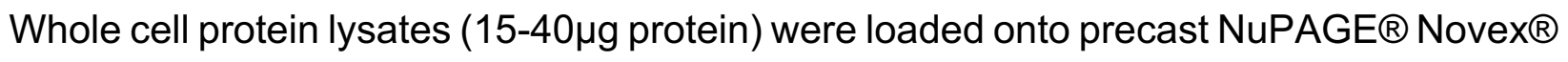
$4-12 \%$ Bis-Tris gels, run $1 \mathrm{hr}$ at $120 \mathrm{~V}$. Gel electrophoresis separated proteins were transferred onto a PVDF membrane or nitrocellulose membrane using a Turboblotter (Bio-Rad). The membrane was first blocked with B-TBST (TBS buffer with $0.05 \%$ Tween20 and supplemented with 5\% blotting grade non-fat dry milk; Bio-Rad) for $1 \mathrm{hr}$ at room temperature and subsequently blotted with the primary antibodies in B-TBST overnight at $4^{\circ} \mathrm{C}$. The primary antibodies and their dilutions are listed in the Key Resource Table. After washing, membranes were incubated with secondary antibodies in B-TBST for $1 \mathrm{hr}$ (room temperature). The following HRP conjugated secondary antibodies were used: BioRad Goat anti-mouse-HRP conjugate and Bio-Rad anti-rabbit-HRP conjugate (see Key Resource Table). After washing, the membrane was illuminated with a chemiluminescent substrate. Protein bands were imaged using a Bio-Rad Chemi-Doc MP imaging system.

\section{MIDAS}

MIDAS (for Modular Irradiation, Detection, and Analysis System) is a flexible, userfriendly and integrated software platform for start-to-finish performance and statistical 
analysis of micro-irradiation experiments. It is Modular in that each component offers the user multiple complementary approaches that may be freely combined. The Irradiation component is currently implemented as a macro written for NIS-Elements, which provides a graphical user interface (GUI) for choosing settings for laser wavelength, power, irradiation pattern(s), and image acquisition. Irradiation patterns and image acquisition can be tailored for time-lapse video of live cells expressing fluorescently labeled molecules of interest, for fixative-based staining following irradiation, or for combined approaches. Time-lapse irradiation experiments can be performed in parallel, with multiple cells in a single field being irradiated and then imaged collectively, or in series, where a selected group of cells are stimulated and imaged in sequence. Both approaches irradiate cells sequentially - the parallel module measures the duration of each irradiation event and applies a per-cell timing offset to accurately measure time post-irradiation when imaged. For fixative-based staining, a custom image registration algorithm is used to precisely re-locate the image field following sample preparation. After irradiation and image acquisition, the Detection component guides the user through the semi-automated measurement process, allowing for user supervision and intervention if necessary, while easing workflow by automating repetitive tasks. This component is implemented as a script for FIJI written in the Jython language, and features modes for measuring serial video, parallel video, or individual stained images. After data have been measured and output to a summary file, the Analysis component is used for visualization and statistical analysis of multiple datasets. This component is written in Python, using the Matplotlib and Numpy libraries for data processing. Data can be viewed at single-cell resolution or as averaged populations, with multiple normalization options to foreground different aspects of the data: normalized to a reference to minimize cell-to-cell variability, normalized to per-cell maximum intensity to emphasize differences in timing, and normalized to a pre-irradiation image to emphasize differences in intensity. To quantitatively assess features of recruitment data, three measurements are made for each intensity trace: time to peak recruitment intensity, half-life of recruitment, and relative peak intensity. Time to peak is defined as the time at which recruitment intensity crosses a threshold set to the $95 \%$ confidence interval of the maximum intensity for that cell. Half- 
life of recruitment is defined as the time post-peak at which the intensity crosses a lower threshold set to the same confidence interval of $50 \%$ of the maximum intensity. Relative peak intensity is defined as the ratio of maximum intensity per cell to the pre-irradiation intensity of that cell. Data are then analyzed statistically, and standard errors of the mean are reported. For record keeping and downstream analysis/visualization, an Excel format spreadsheet is generated, including all raw data, normalizations, measured features, statistical analyses, and experimental settings. To ensure data integrity and record keeping, although data may be excluded from analyses by the user, these data are still included in the summary spreadsheet, although plainly marked as excluded from analysis. MIDAS was developed and implemented at the USA Mitchell Cancer Institute (J.F.A.), with invaluable conceptual input from Dr. Natalie Gassman.

\section{Laser micro-irradiation}

For laser micro-irradiation, $5 \times 10^{4}$ cells were seeded into a 4-chamber glass bottom vessel (Thermo Fisher Scientific, \#155382). 24 hours later, laser micro-irradiation was performed using a Nikon A1r confocal microscope. Live cells were imaged with a Nikon A1rsi laser scanning confocal microscope equipped with 6 visible wavelength lasers $(405,441,514$, $561,647 \mathrm{~nm}$, Coherent), customized to add a UVA 355nm laser (PicoQuant) controlled by a Brueker XY Galvanometer, and equipped with a live-cell incubation chamber (Tokai Hit) maintained at $5 \% \mathrm{CO}_{2}$ and $37^{\circ} \mathrm{C}$, using a $40 \mathrm{x}$ oil-immersion objective. For each experiment, a field was selected, and cells were irradiated using a custom microirradiation script implemented in NIS-Elements. A $355 \mathrm{~nm}$ laser or a $405 \mathrm{~nm}$ laser (as indicated) was used for micro-irradiation, with stimulation times varying from $1 \mathrm{~s}-2.5 \mathrm{~s}$ per site. Time lapse images were collected every 15 seconds during a 10 minute interval. Images of focal recruitment were quantified using MIDAS to both detect focal recruitment and statistically analyze image results. Forty individual cells (2 sets of 10 cells were performed on 2 separate days) were analyzed and used to generate recruitment profiles and kinetic parameters. 


\section{Immunofluorescence confocal microscopy}

For poly(ADP-ribose) (PAR) analysis by immunocytochemistry, $5 \times 10^{4}$ cells were seeded into a 4-chamber glass bottom vessel (Thermo Fisher Scientific, \#155382). Cells were laser micro-irradiated at $405 \mathrm{~nm}$ then subsequently fixed with $4 \%$ PFA for 10 min and briefly permeabilized with $0.1 \%$ TritonX-100 solution in PBS. Cells were rinsed with PBS and blocked in blocking buffer (10\% normal goat serum in PBS) for $30 \mathrm{~min}$ and subsequently incubated with the PAR primary antibody for 1 to $2 \mathrm{hrs}$ at $37^{\circ} \mathrm{C}$, followed by three PBS washes and an incubation with fluorescent goat anti-mouse secondary antibody (see Key Resources Table for primary and antibodies used, with dilutions for each). Nuclei were stained with NucBlue dye. Fixed cells were imaged with a Nikon A1rsi laser scanning confocal microscope, using a 40x oil-immersion objective.

\section{Spectral Imaging of A549-POLBHR-EGFP cells}

For spectral separation of low intensity EGFP visualization, spectral images were obtained with a Nikon A1rsi laser scanning confocal microscope using $488 \mathrm{~nm}$ laser for excitation, and collecting 14 bands from $500.2 \mathrm{~nm}$ to $638.4 \mathrm{~nm}$, with a spectral gating resolution set to $10 \mathrm{~nm}$. Spectra were collected from parental and A549/EGFP-Pol $\beta$ cells to provide spectra for autofluorescence and EGFP, respectively. Spectral unmixing was performed in NIS-Elements.

\section{NAD ${ }^{+} / \mathrm{NADH}$ Analysis}

The level of $\mathrm{NAD}^{+}$and $\mathrm{NADH}$ in cells was measured using the Enzychrome NAD /NADH colorimetric assay kit (BioAssay Systems), following the supplier-provided protocols with minimal changes, as we have described previously (Wilk et al., 2020). Cells were seeded in a 6-well plate at a density of $2 \times 10^{5}$ cells per well for $\mathrm{NAD}^{+}$measurements and $3 \times 10^{5}$ cells per well for $\mathrm{NAD}^{+}$pool measurements (NAD+ plus NADH). 24 hrs later, cells were treated with the $\mathrm{NRH}(100 \mu \mathrm{M})$ for $0,0.5,1,2,4,8$ and 24 hours or with FK866 (50 $\mathrm{nM}$ ) for 24 hours. Following treatment, cells were harvested and a suspension of $2 \times 10^{5}$ cells was divided in half for measuring $\mathrm{NAD}^{+}$and $\mathrm{NADH}$, respectively, or a suspension of $1 \times 10^{5}$ cells was used for the $\mathrm{NAD}^{+}$measurement only. Cell pellets were 
homogenized using plastic pestles and the extraction of $\mathrm{NAD}^{+}$and $\mathrm{NADH}$ was performed in the provided lysis buffers. Extracts were heated at $60^{\circ} \mathrm{C}$ for $5 \mathrm{~min}$ and neutralized with the provided buffers. Samples were spun down and the supernatant was immediately used for measurements of $\mathrm{NAD}^{+} / \mathrm{NADH}$ content using a Microplate Reader (BioTek) at $565 \mathrm{~nm}$.

\section{Statistical analysis}

Averages and standard error of the mean (SEM) were calculated from the means (on technical replicates) of multiple independent experiments $(n=$ number of independent experiments as indicated in figure legends) unless stated otherwise. Student t-test and ANOVA was used to test for significant differences as appropriate, with results generally compared to controls and as indicated in the figure legends. P-values are indicated by asterisks with: ${ }^{*} p<0.05,{ }^{* *} p<0.01$. Statistical analyses were performed using GraphPad PRISM except those explicitly determined in MIDAS. 


\section{References Cited}

Fang, Q., Andrews, J., Sharma, N., Wilk, A., Clark, J., Slyskova, J., Koczor, C.A., Lans, H., Prakash, A., and Sobol, R.W. (2019). Stability and sub-cellular localization of DNA polymerase beta is regulated by interactions with NQO1 and XRCC1 in response to oxidative stress. Nucleic Acids Res 47, 6269-6286.

Fang, Q., Inanc, B., Schamus, S., Wang, X.H., Wei, L., Brown, A.R., Svilar, D., Sugrue, K.F., Goellner, E.M., Zeng, X., et al. (2014). HSP90 regulates DNA repair via the interaction between XRCC1 and DNA polymerase beta. Nature communications 5, 5513.

Fouquerel, E., Goellner, E.M., Yu, Z., Gagne, J.P., Barbi de Moura, M., Feinstein, T., Wheeler, D., Redpath, P., Li, J., Romero, G., et al. (2014). ARTD1/PARP1 negatively regulates glycolysis by inhibiting hexokinase 1 independent of NAD+ depletion. Cell reports $8,1819-1831$.

Giroud-Gerbetant, J., Joffraud, M., Giner, M.P., Cercillieux, A., Bartova, S., Makarov, M.V., Zapata-Perez, R., Sanchez-Garcia, J.L., Houtkooper, R.H., Migaud, M.E., et al. (2019). A reduced form of nicotinamide riboside defines a new path for $N A D(+)$ biosynthesis and acts as an orally bioavailable $\mathrm{NAD}(+)$ precursor. Mol Metab 30, 192202.

Sanjana, N.E., Shalem, O., and Zhang, F. (2014). Improved vectors and genome-wide libraries for CRISPR screening. Nat Methods 11, 783-784.

Schindelin, J., Arganda-Carreras, I., Frise, E., Kaynig, V., Longair, M., Pietzsch, T., Preibisch, S., Rueden, C., Saalfeld, S., Schmid, B., et al. (2012). Fiji: an open-source platform for biological-image analysis. Nat Methods 9, 676-682.

Slyskova, J., Sabatella, M., Ribeiro-Silva, C., Stok, C., Theil, A.F., Vermeulen, W., and Lans, H. (2018). Base and nucleotide excision repair facilitate resolution of platinum drugs-induced transcription blockage. Nucleic Acids Res 46, 9537-9549.

Sykora, P., Witt, K.L., Revanna, P., Smith-Roe, S.L., Dismukes, J., Lloyd, D.G., Engelward, B.P., and Sobol, R.W. (2018). Next generation high throughput DNA damage detection platform for genotoxic compound screening. Sci Rep 8, 2771. 
Wilk, A., Hayat, F., Cunningham, R., Li, J., Garavaglia, S., Zamani, L., Ferraris, D.M., Sykora, P., Andrews, J., Clark, J., et al. (2020). Extracellular NAD(+) enhances PARPdependent DNA repair capacity independently of CD73 activity. Sci Rep 10, 651. 
bioRxiv preprint doi: https://doi.org/10.1101/2021.04.01.437913; this version posted April 4, 2021. The copyright holder for this preprint (which was not certified by peer review) is the author/funder. All rights reserved. No reuse allowed without permission.

Koczor et al.

Figure 2

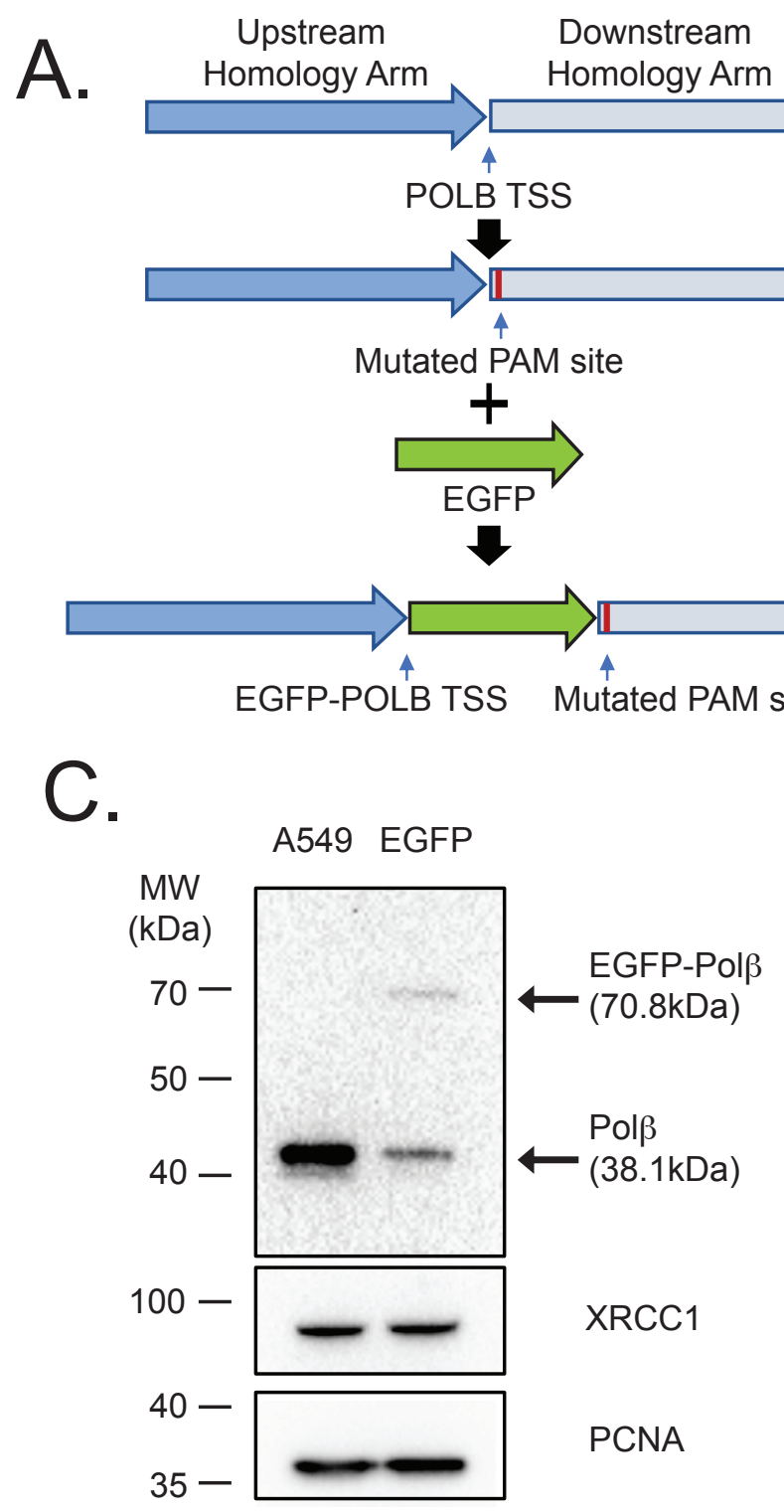

Allele 1:

No Insertion

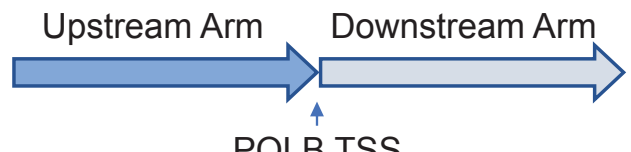

Allele 2:

EGFP Insertion

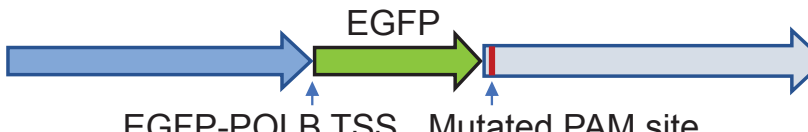

Allele 3:

Partial Insertion
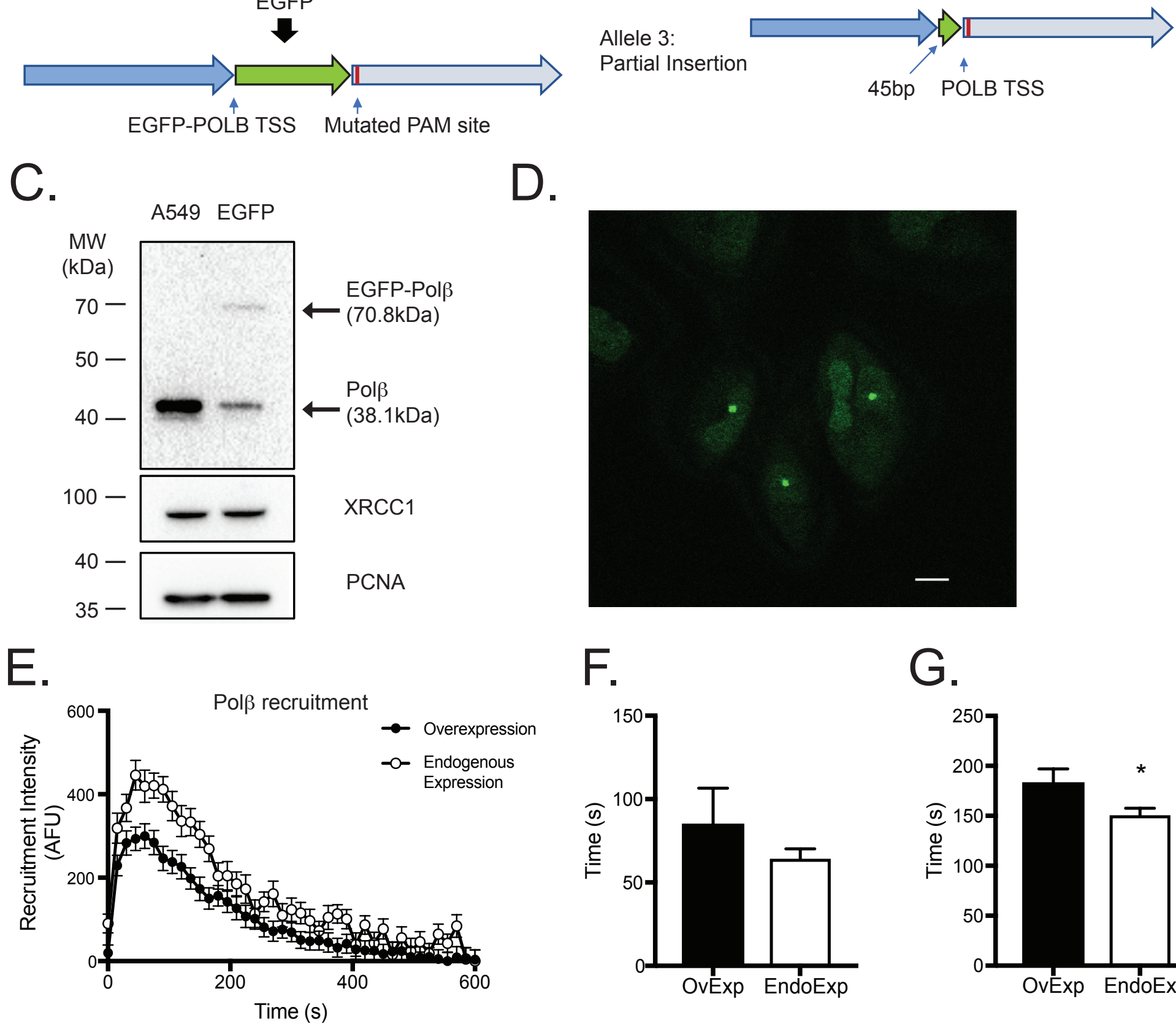

F.

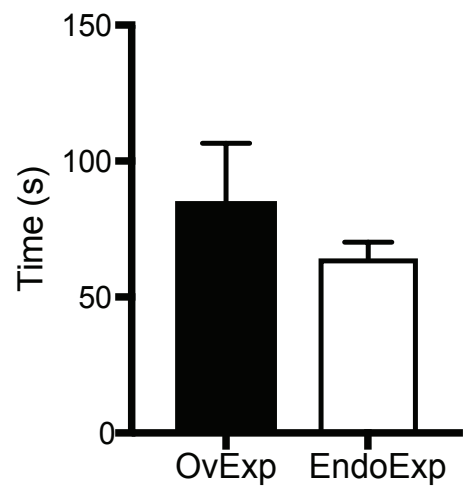

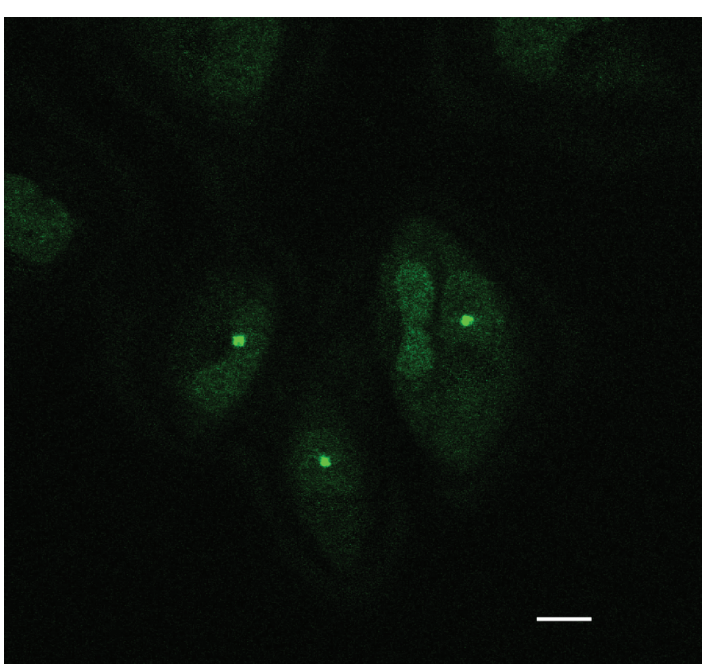

G.

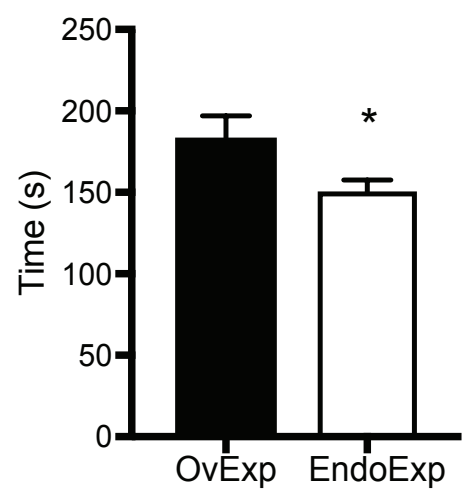


Koczor et al.
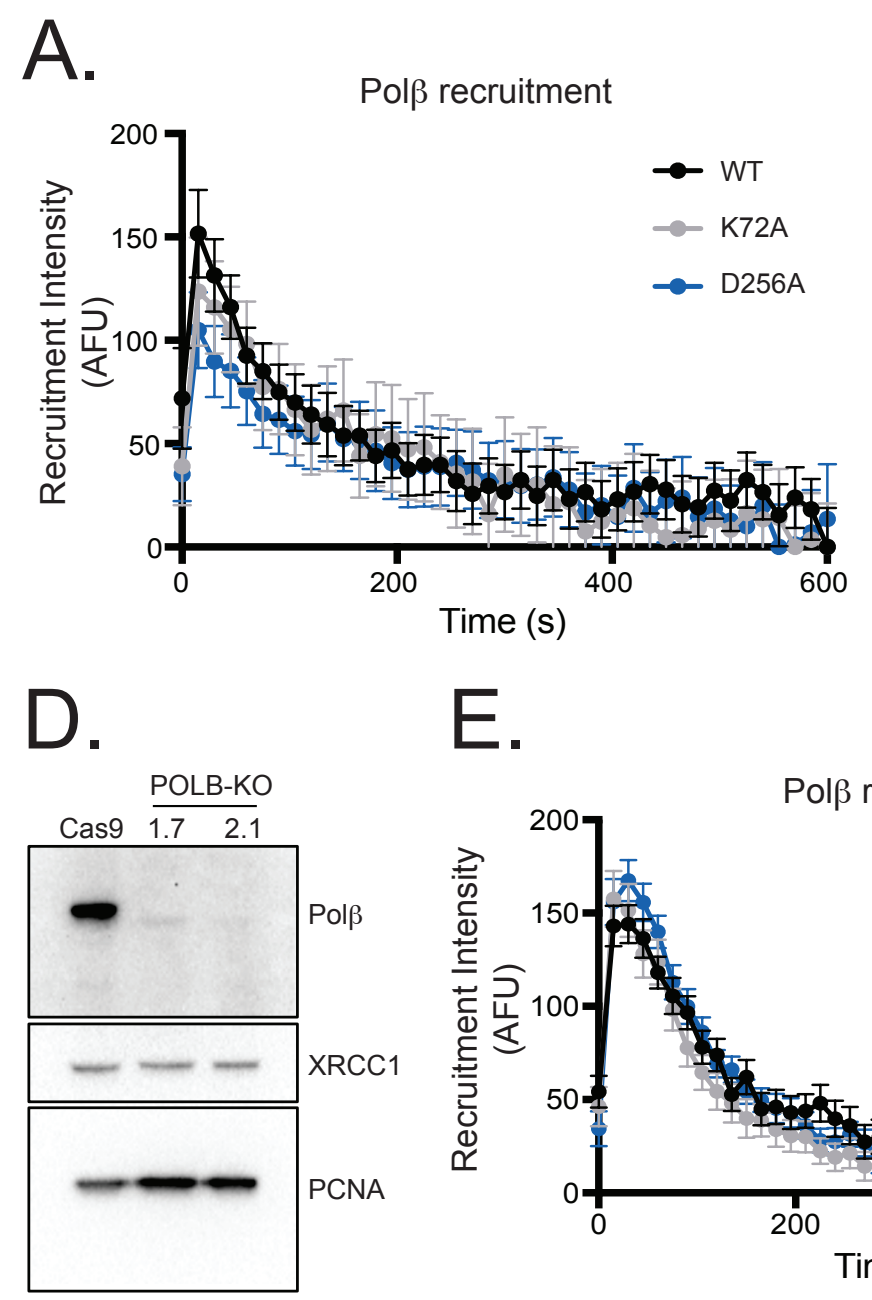
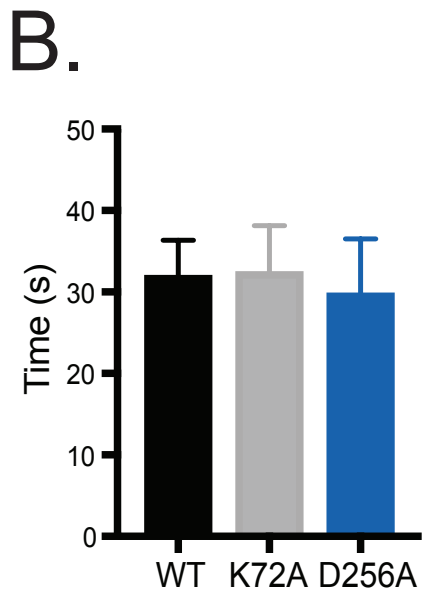

Figure 3
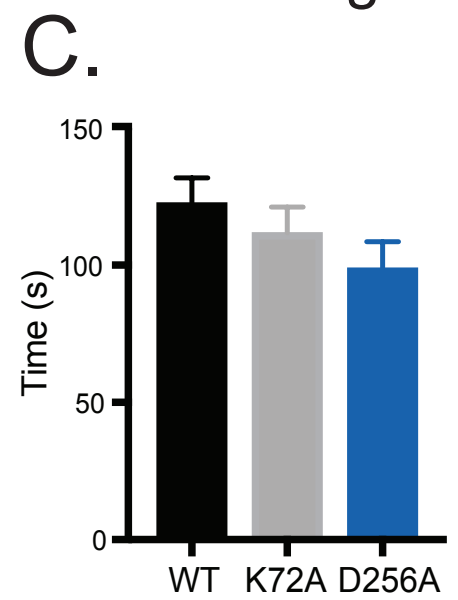

F.
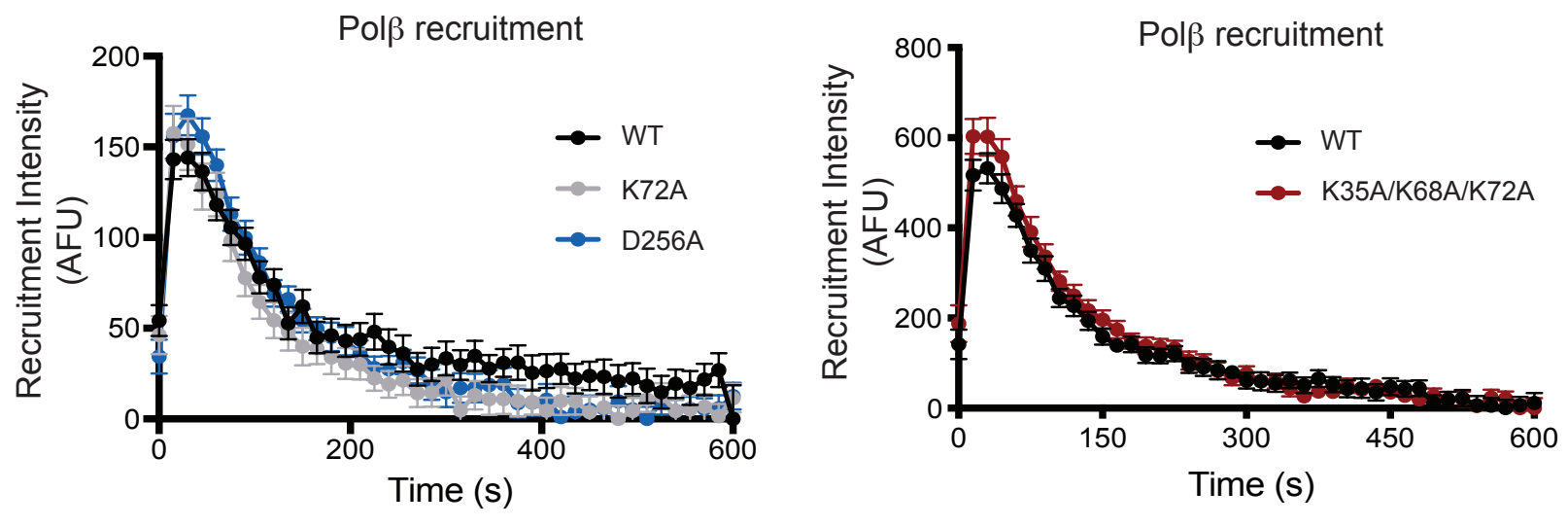
A.
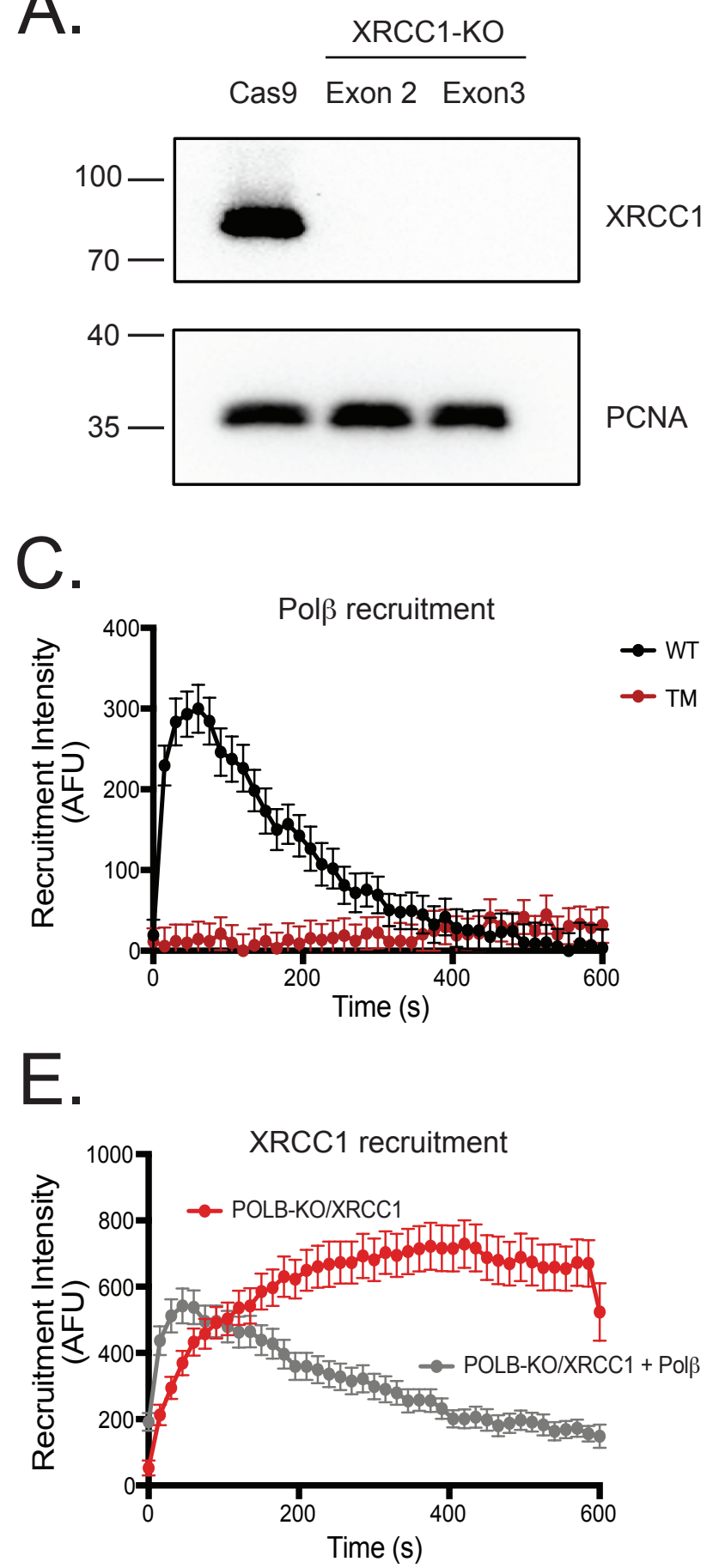
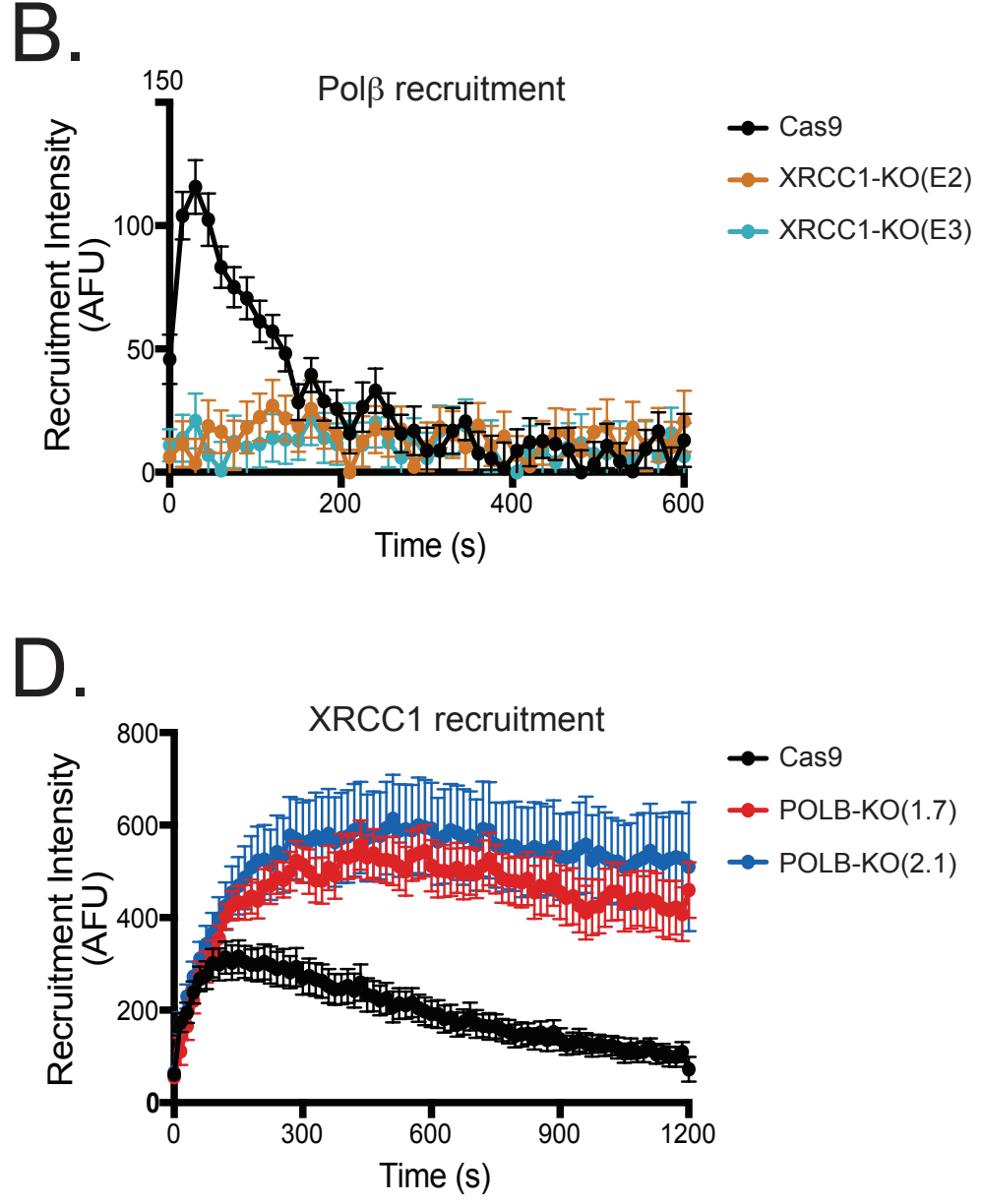

F.

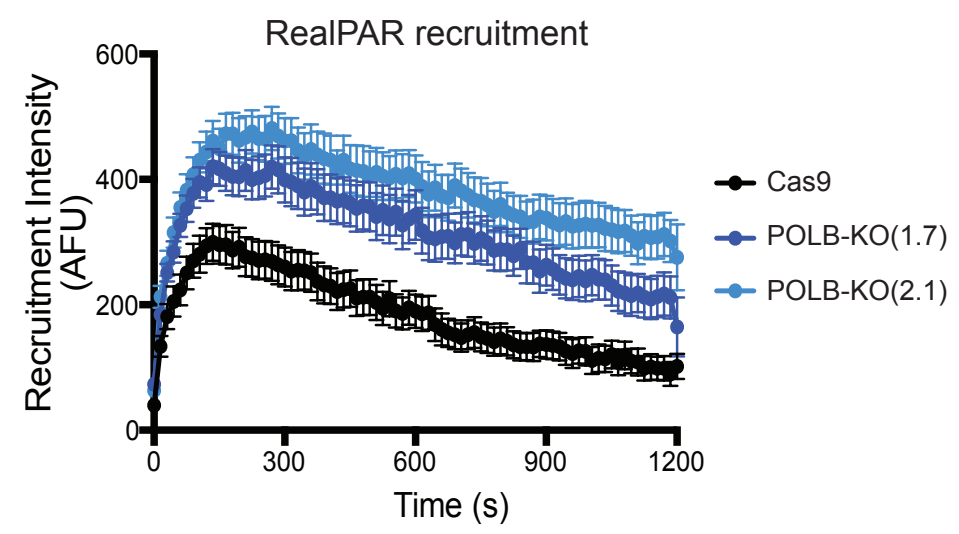


bioRxiv preprint doi: https://doi.org/10.1101/2021.04.01.437913; this version posted April 4, 2021. The copyright holder for this preprint (which was not certified by peer review) is the author/funder. All rights reserved. No reuse allowed without permission.

Koczor et al.

Figure 5

A.
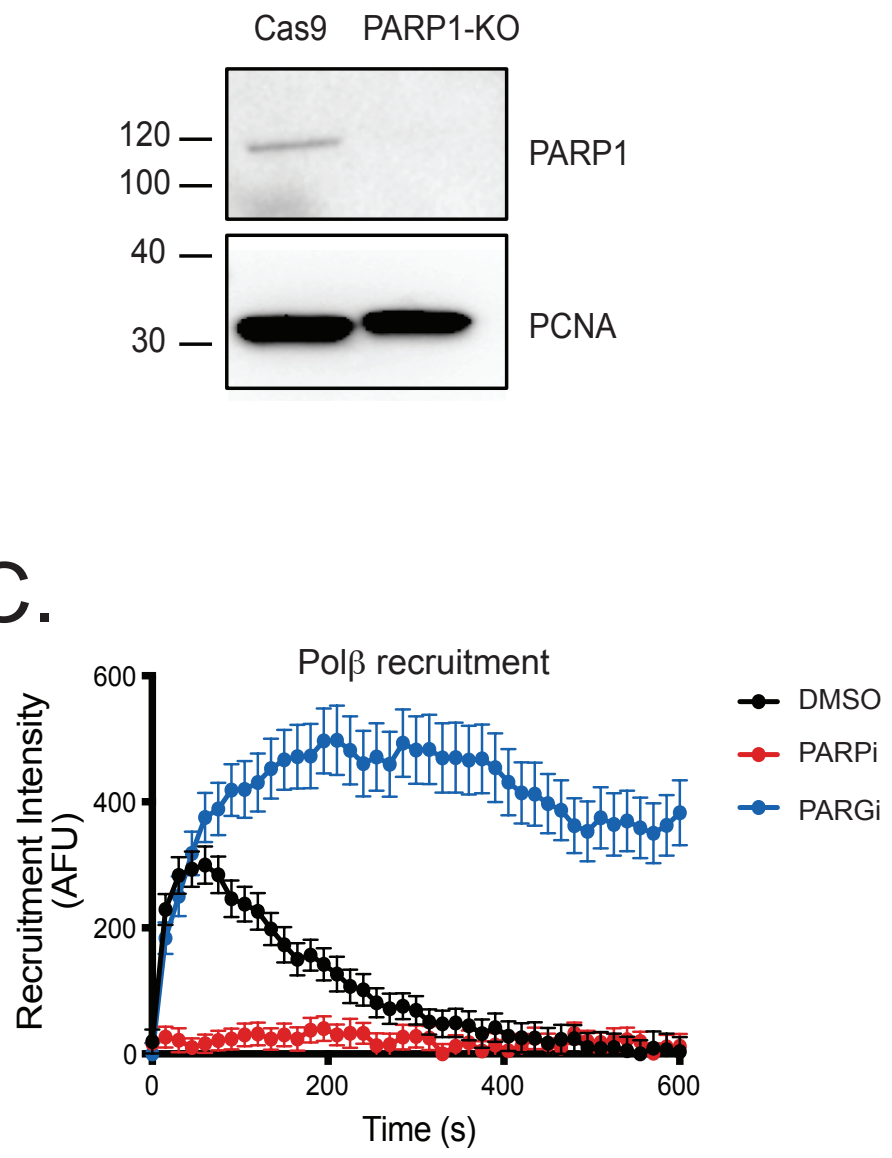

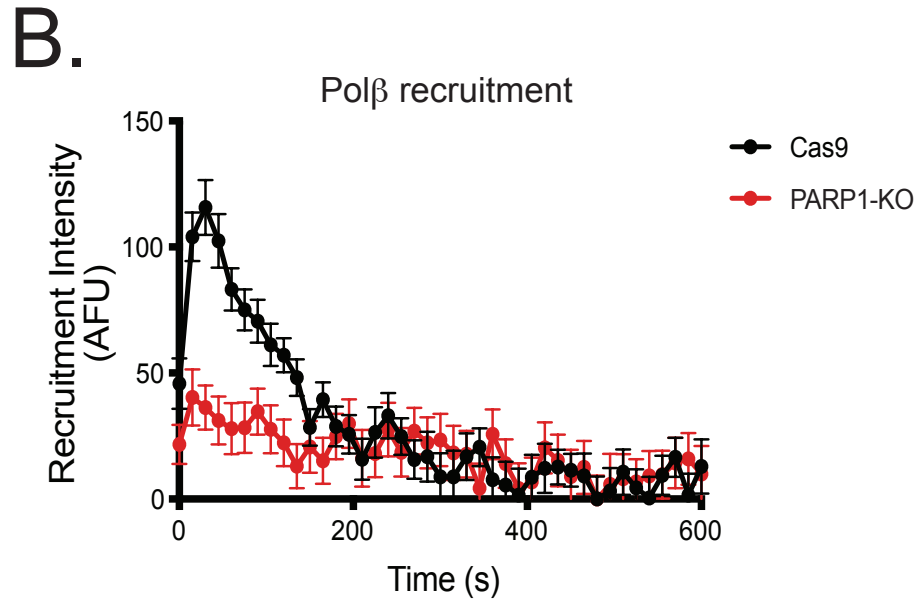

D.

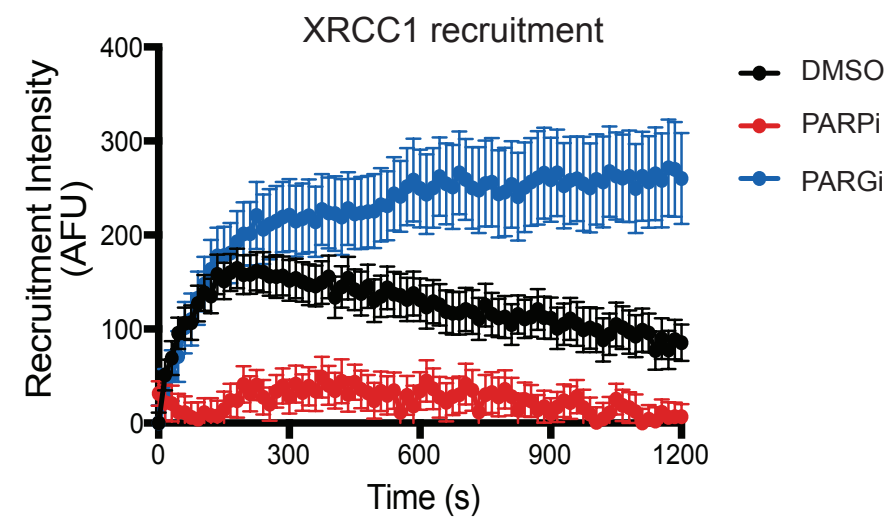




\section{Koczor et al.}

A.

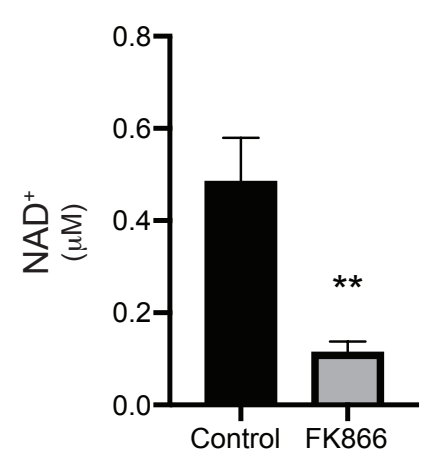

B.

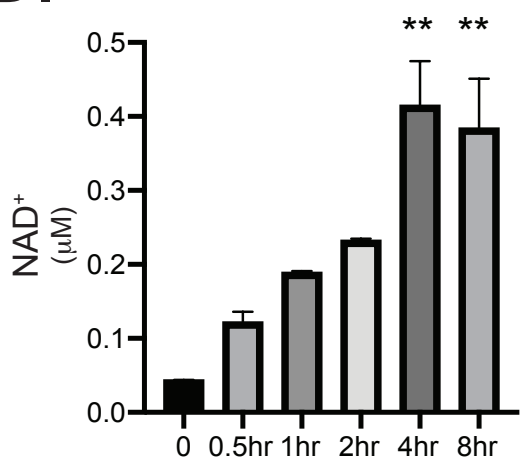

A549

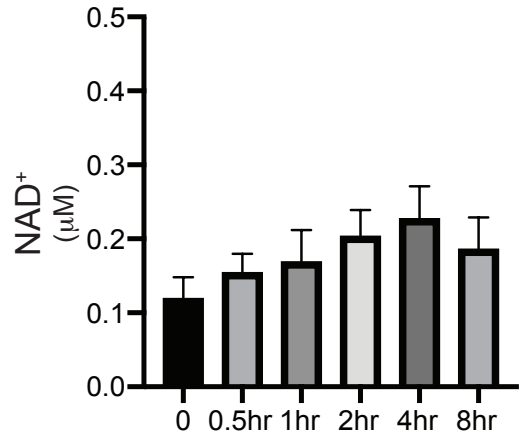

C.

PAR

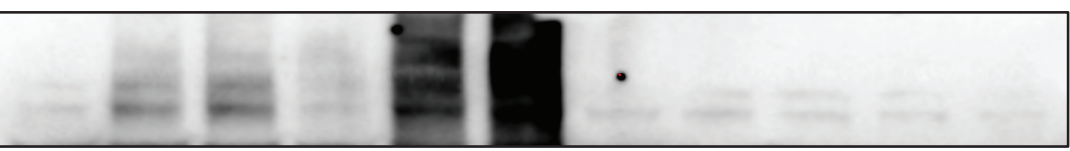

$\gamma-\mathrm{H} 2 \mathrm{~A} . \mathrm{X}$

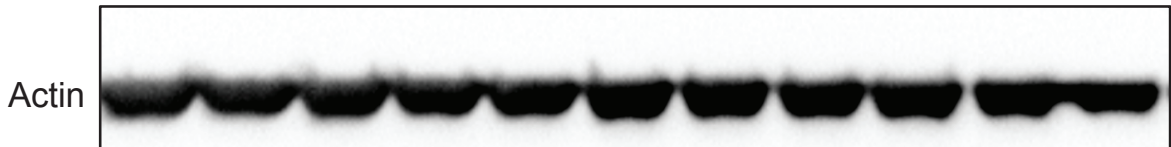

$\begin{array}{rccccccccccc}100 \mu \mathrm{M} \mathrm{H}_{2} \mathrm{O}_{2} & - & + & - & - & + & - & - & + & - & - & - \\ 300 \mu \mathrm{M} \mathrm{H}_{2} \mathrm{O}_{2} & - & - & + & - & - & + & - & - & + & + & + \\ 100 \mu \mathrm{MRH} N & - & - & - & + & + & + & - & - & - & - & + \\ 50 \mathrm{nM} \mathrm{FK866} & - & - & - & - & - & - & + & + & + & - & - \\ 10 \mu \mathrm{M} \text { ABT888 } & - & - & - & - & - & - & - & - & - & + & +\end{array}$

$\mathrm{D}$

Pol $\beta$ recruitment

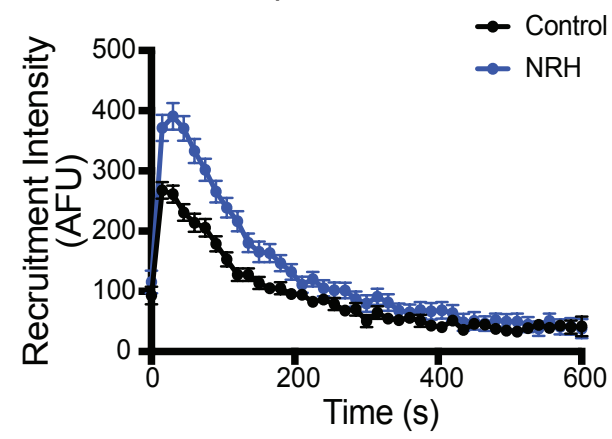

$G$

促

Pol $\beta$ recruitment

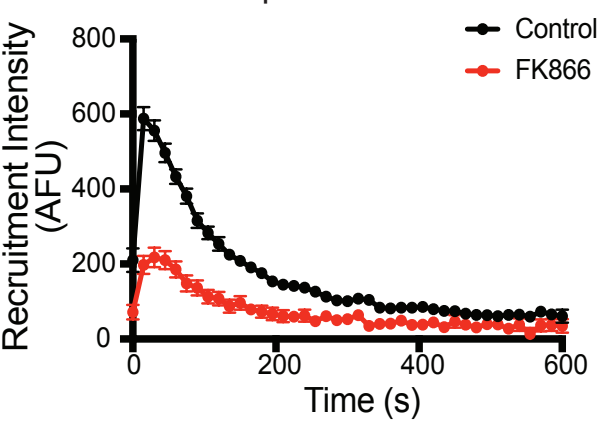

E. XRCC1 recruitment

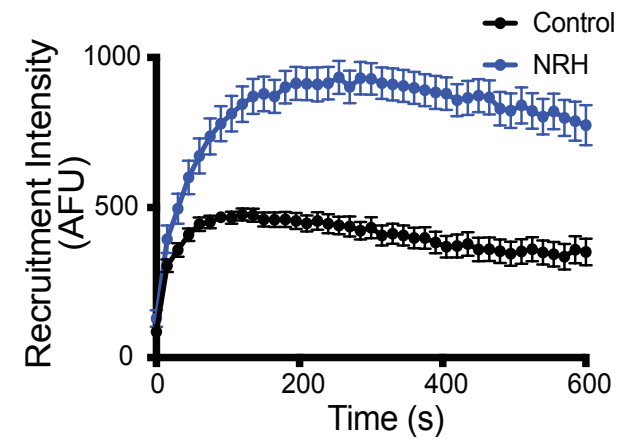

$\mathrm{H}$.

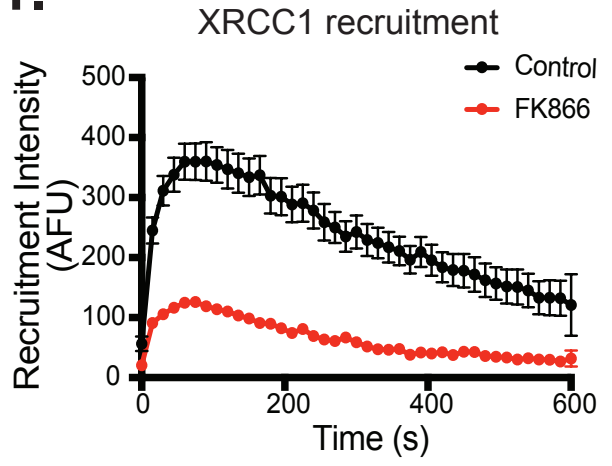

F. RealPAR recruitment

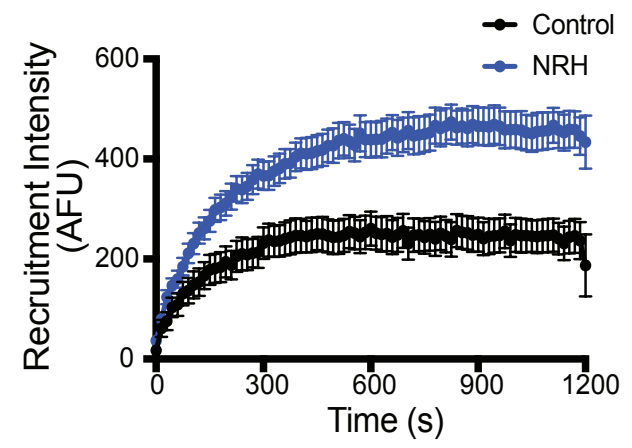

RealPAR recruitment

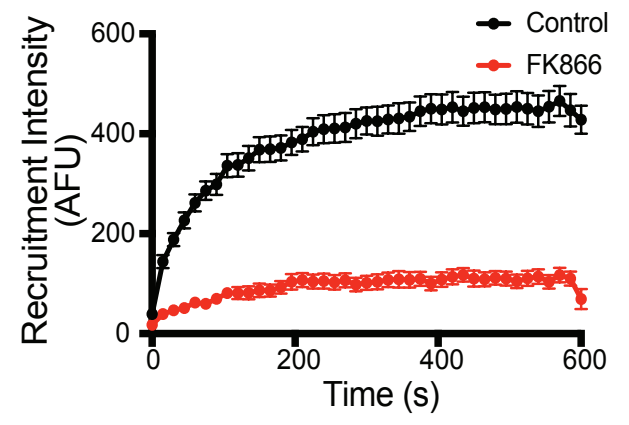




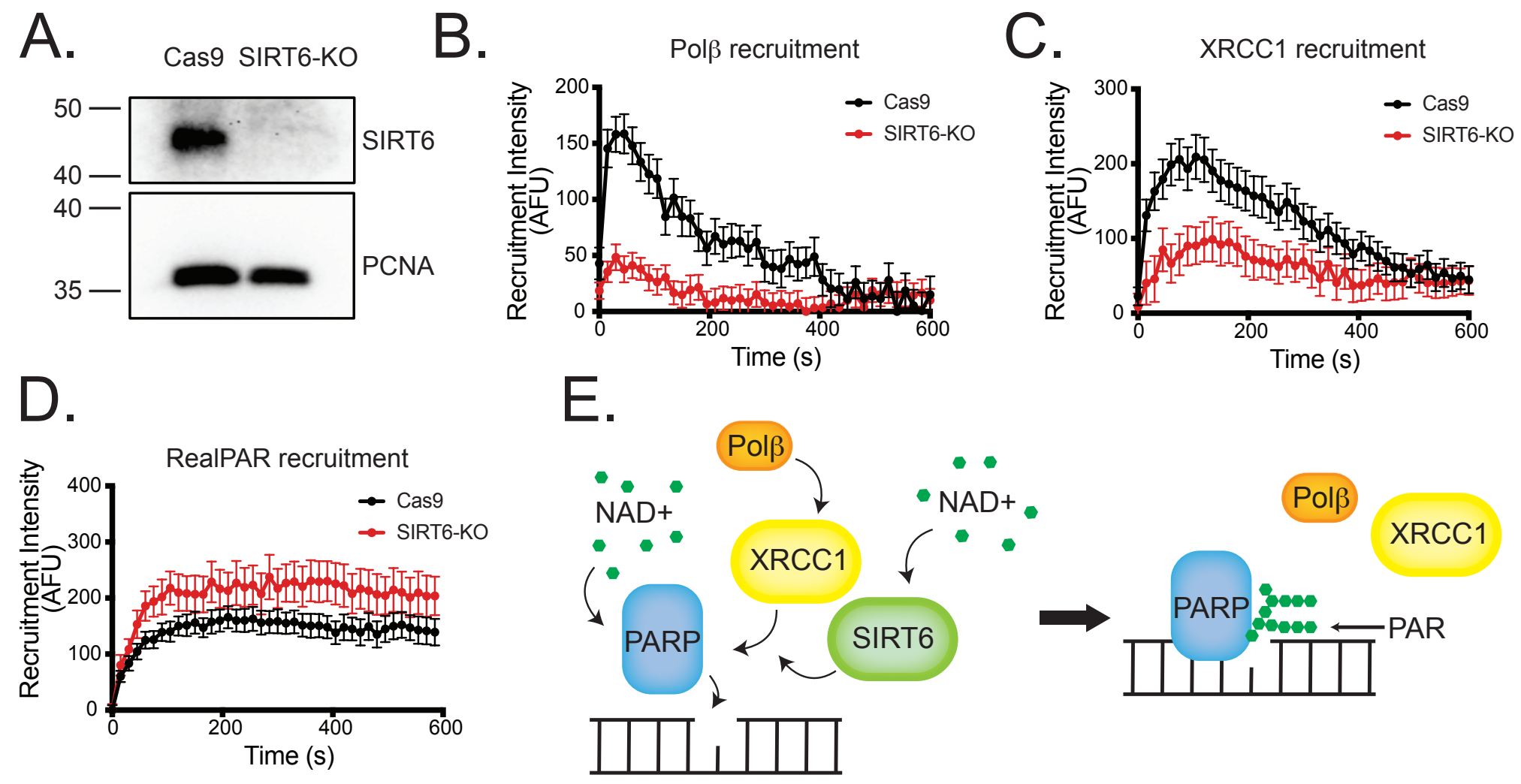

